\title{
Environmental regulation of firms that experience dynamic inconsistency
}

\author{
by \\ James Zuccollo
}

\begin{abstract}
A thesis
submitted to the Victoria University of Wellington in fulfilment of the requirements for the degree of Master of Commerce and Administration in Economics.

Victoria University of Wellington
\end{abstract}




\begin{abstract}
The recent push for environmental regulation has invigorated the discussion of mechanism design and optimal taxation policy. Recent decades have also seen growing interest in behavioural economics and empirically based theory. In this thesis we take a step towards combining the two by asking how a regulator may correct an externality in situations where they have a time consistency problem.

Time inconsistency is one of the notable developments of behavioural economics. It posits that an agent's decisions do not remain consistent over time, which causes a utility loss if the agent cannot commit themselves to a particular course of action and stick to it. The solution to inconsistency problems is to precommit to a course of action and prevent future deviations from it. However, finding a mechanism to enable such precommitment is often problematic.

A regulator who maximises welfare can have a time consistency problem because welfare will depend on the decisions of firm and households who may themselves be inconsistent. That inconsistency then propagates to the regulator's decision and reduces the level of welfare that the regulator can reach. Alternatively, the regulator's time consistency problem can be caused by non-stationarity in their time preferences. To reach the firstbest outcome the regulator must not only eliminate the environmental externality: they must also overcome their own time inconsistency problem.
\end{abstract}


This thesis draws from the literature on strategic delegation to construct a taxation game in which the regulator can achieve the first best taxation regime without the need for external precommitment devices. We study a dynamic game where the regulator chooses a tax rate and the regulated monopolist chooses their price. We show that the Markov-perfect equilibrium price path of this game will replicate the first best plan. Our results holds for time inconsistency caused by both jump states and quasihyperbolic discounting. 


\section{Acknowledgments}

Thanks to my supervisor Vladimir Petkov for his unerring support and my secondary supervisor, Jacek Krawczyk for providing sound advice throughout. 


\section{Contents}

1 Introduction 1

2 Theoretical framework 3

2.1 Dynamic games . . . . . . . . . . . . . . 4

2.1.1 Features of dynamic games . . . . . . . . . 4

2.1.2 Open loop vs feedback strategies . . . . . . . . 5

2.1 .3 State variables . . . . . . . . . . . 6

2.1.4 Markov strategies . . . . . . . . . . 7

2.2 Dynamic consistency . . . . . . . . . . . . 8

2.2.1 Dynamic consistency and precommitment . . . . 8

2.2.2 Time-consistency and perfection ......... 9

2.2.3 Sufficient conditions for time-consistency . . . . . . . 11

2.2.4 Implications of dynamic inconsistency for regulation 12

2.3 Causes of regulatory dynamic inconsistency . . . . . . . . 14

2.3.1 Inconsistency of the welfare function $\ldots . . . . .14$

2.3.2 Industries in which dynamic inconsistency arises . . 15

3 Problem 17

3.1 A model of a dynamically inconsistent regulator . . . . . . 18 
3.1.1 The consumption decision . . . . . . . . . 18

3.1.2 The production decision . . . . . . . . . 22

3.1 .3 The regulator's decision . . . . . . . . . . 23

3.2 Laissez-faire performance . . . . . . . . . . . . 24

3.2.1 The monopolist's price path . . . . . . . . . . 25

3.2.2 Inefficiency of the laissez-faire outcome . . . . . . . 27

3.3 Benchmarking regulatory performance . . . . . . . . . 28

3.3.1 First-best price plan . . . . . . . . . . . . 29

3.3.2 Second-best price path . . . . . . . . . . . 31

4 Proposition 34

4.1 Strategic delegation . . . . . . . . . . . . 35

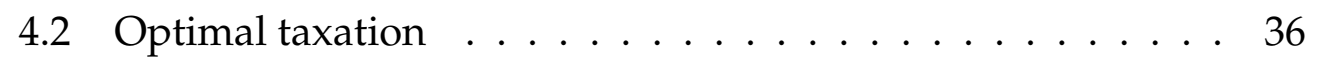

4.2.1 A regulatory model . . . . . . . . . . . 37

4.2 .2 Timing ................... 40

4.2.3 The equilibrium of the regulation game . . . . . . . 41

4.2.4 Resolving the regulator's time inconsistency . . . . . 43

4.2 .5 Equilibrium strategies . . . . . . . . . . . 44

4.3 Comparison with benchmarks . . . . . . . . . . . . 45

5 Computation $\quad 47$

5.1 Defining the model . . . . . . . . . . . . . . . . 48

5.1 .1 The demand function $\ldots \ldots \ldots . \ldots 48$

5.1 .2 The welfare function $\ldots \ldots \ldots \ldots$

5.2 Solving the model . . . . . . . . . . . . . . . . . . 49

5.3 Base case . . . . . . . . . . . . . . . . . 50

5.4 Varying parameters . . . . . . . . . . . . 53 
5.4.1 Convergence across parameter values . . . . . . . 54

5.4.2 Steady states across parameter values . . . . . . . 58

6 Hyperbolic discounting $\quad 61$

6.1 Quasi-hyperbolic discounting . . . . . . . . . . . 62

6.2 The quasi-hyperbolic model . . . . . . . . . . . . 63

6.3 Elements of the model . . . . . . . . . . . . . . . 63

6.3 .1 The consumer . . . . . . . . . . . . 63

6.3 .2 The monopolist . . . . . . . . . . . . . 64

6.3 .3 The regulator . . . . . . . . . . . . 64

6.4 Laissez-faire equilibrium . . . . . . . . . . . . . . 65

6.5 Benchmarking regulation . . . . . . . . . . . 66

6.5 .1 First best regulation . . . . . . . . . . 66

6.5.2 Comparison to laissez-faire outcome . . . . . . . . 67

6.5 .3 Second best regulation . . . . . . . . . . . . . 69

6.6 Regulation with delegation $\ldots \ldots \ldots 70$

6.6.1 The welfare function . . . . . . . . . 70

6.6 .2 The profit function .............. 71

6.6 .3 The taxation game ............... 72

$\begin{array}{lll}7 & \text { Conclusions } & 75\end{array}$

$\begin{array}{ll}\text { A Concavity proof } & 77\end{array}$

$\begin{array}{ll}\text { B Durable equilibria } & 79\end{array}$

B.1 Time-consistency without precommitment . . . . . . . . 79

B.2 MPE of the taxation game . . . . . . . . . 80 
CONTENTS $\mathrm{v}$

$\begin{array}{ll}C \text { Numerical results } & 83\end{array}$

D Hyperbolic derivations $\quad 87$

D.1 First best regulation . . . . . . . . . . . . . . 87

D.2 Second best regulation . . . . . . . . . . . . 88

D.3 The regulation game . . . . . . . . . . . . . . 89

D.3.1 The regulator's problem . . . . . . . . . . . . 89

D.3.2 The monopolist's problem . . . . . . . . . . 90 


\section{Chapter 1}

\section{Introduction}

Environmental protection has become the political cause célèbre of the twenty-first century. Politicians in the European Union and New Zealand alike are scrambling to seize the moral high ground on the issue of environmental regulation. For many countries, the idea of a tax on pollution is very attractive, both economically and politically. In this context it is opportune to examine any difficulties that may arise in the creation of optimal regulatory schemes.

Economists have long recognised the problems posed by externalities. There is a large body of literature on regulation that is designed to overcome the negative externality imposed on society by polluters. One mechanism features prominently in the environmental literature is taxation. Pigouvian taxation is not only theoretically effective for mitigating externalities; it is also a mechanism that is relatively easy for regulators to implement. Most governments already have various taxes in place, so creating a pollution tax is a task for which the administrative infrastructure already exists. 
Unfortunately, governments can face certain difficulties in implementing efficient taxation. This thesis will examine regulating an industry where agents exhibit dynamically inconsistent behaviour. In such an industry, a regulator who maximises some welfare function that accounts for industry profits will find that his policies may also suffer from time consistency problems. If the government cannot precommit to future taxes, it will be unable to achieve the first-best outcome for society. We propose a taxation mechanism which allows the regulator to overcome his dynamic inconsistency problem, and thus realise the first-best regulatory outcome.

Chapter 2 canvasses the theoretical framework of dynamic inconsistency that underlies the proposed mechanism. Chapter 3 constructs a model of a polluting monopolist producing a durable good and a regulator attempting to address the pollution problem. This model is used to demonstrate the that the inability of the regulator to precommit to future actions will prevent him from achieving the first-best outcome. Chapter 4 describes the proposed Pigouvian taxation mechanism. The method by which it overcomes the dynamic inconsistency problem and implements efficiency is explained. Since the model does not permit a closed-form solution, we develop a numerical example in chapter 5 to investigate the effect of parameter variations. 


\section{Chapter 2}

\section{Theoretical framework}

The following section discusses the theoretical framework of the thesis. The game theoretic context of the problem is explained, as is the reason for choosing to focus on the regulation of pollution.

Section 2.1 briefly covers the theory of dynamic games and specifies the type of games that will be considered. Section 2.2 explores the notion of dynamic inconsistency. Here the type of dynamic inconsistency that affects the model in chapter 3 will be delineated. Section 2.3 surveys the types of situations such inconsistency problems may occur.

The innovation of this thesis is to design a taxation mechanism that will aid a government which regulates a polluter while experiencing dynamic inconsistency. The aim is to show that this regulator can use taxes as an instrument that provides polluters with efficient incentives even when his welfare maximisation problem contains a jump variable. 


\subsection{Dynamic games}

\subsubsection{Features of dynamic games}

Static game theory studies the interaction of strategic agents in a so-called 'one-shot' framework. Each player makes a one-time decision, and there is no future play. Such games can be described as static, since they do not have any dynamic element. In reality, many important decisions occur in the context of ongoing relationships. As a result, the idea of a repeated game (also called a supergame) was developed.

In a repeated game, the one-shot game is played multiple times by the same players. These games may produce results unobtainable in static games (e.g. cooperation in the infinite horizon Prisoners' Dilemma). However, they cannot capture some important features of many observed relationships, because the context of the play is the same in every period. In real life, it is often the case that one's actions today affect one's possible future actions, and thus potential future payoffs. Repeated games do not acocunt for such inter-temporal linkages. It is these interactions that dynamic games seek to model. In this thesis, the term 'dynamic game' will refer to games with state dynamics. Repeated games are not within the ambit of dynamic games as the term is used here.

A dynamic game is modelled as a dynamical system in which the state of the world changes over time in response to players' actions. The state variables describe the current state of the system. They may influence the payoffs, or the action space, of the players. The state changes over time according to a pre-defined law of motion, which may depend upon the players' actions. In such a system, players' current actions will affect 
their future payoffs through the state. In addition to the standard static strategic effects, these settings allow for the possibility of inter-temporal strategic effects. Sometimes they also give rise to intra-personal, intertemporal strategic effects: an agent may have a conflict with their future 'self'.

In general, the most popular solution concept in games is that of Nash equilibrium. In dynamic games, various refinements are used to rule out Nash equilibria that may be considered implausible. A couple of these will be explained later in this chapter.

\subsubsection{Open loop vs feedback strategies}

There are two common ways to model players' behaviour in a dynamic game: players could either precommit up front to their future course of action, or they could choose their action in each period based on the current state. The former strategies are known as open loop strategies, as they are non-responsive to changes in the state. The latter strategies are called feedback strategies, because a change in the state can affect the player's actions.

An equilibrium in open loop strategies is justifiable only if players have precommitment power. Indeed, in an open loop equilibrium, players will not change their action in response to deviations from the equilibrium by other players. Essentially, open loop games are static games with a multidimensional action space: instead of choosing one action, at the beginning of time the players choose actions for all periods.

In open loop equilibria, players choose their future actions, while tak- 
ing the future actions of their opponents as given. Constructing strategies in this fashion means that the prescribed actions will often be sub-optimal if the state variable deviates from the anticipated equilibrium path. Thus, open loop strategies are generally not subgame perfect: they will not be optimal in all possible subgames.

When modelling a situation in which players have the ability to respond to deviations of the state, or in other players' strategies, it is more appropriate to consider feedback strategies. This approach specifies the player's strategy as a decision rule, i.e. a function of the state. It is computed while taking as given the decision rules of the other players. Because such strategies are optimal for all possible states, by construction they will be subgame perfect.

\subsubsection{State variables}

Unlike other types of games, in dynamic games players' payoffs can be affected by state variables which change over time. The choice of state variables is an important modelling decision that can have a marked effect upon the outcome of the game.

There are two important types of state variables: first, those that have a direct physical or technological impact upon the game and, secondly, those that affects the psychology of agents and, through it, their behaviour. The first type includes components of the game structure that affect players' payoffs directly, such as pollution stock levels. The second type includes variables that are not payoff-relevant, such as the history of play.

In repeated games, the Folk Theorem establishes that there exist a mul- 
tiplicity of equilibria, provided that players have long memories (Fudenberg and Maskin, 1986). Current research demonstrates that the same result holds for dynamic games in which strategies are allowed to depend on state variables that are not payoff-relevant (Haurie and Pohlohja, 1987; Ausubel and Deneckere, 1989; Gul et al., 1986) . The reason is that equilibrium behaviour is influenced by agents' beliefs about the consequences of deviations from the equilibrium path. Including state variables that affect players' psyche, such as the history of play, can give rise to many possible belief structures. This will result in multiplicity of equilibria. Because it is difficult to draw economic conclusions without a unique prediction, it is common to restrict the state variables to those which directly affect players' payoffs. This restriction does not guarantee a unique equilibrium, but it does reduce the number of possible equilibria.

\subsubsection{Markov strategies}

Strategies that are based on information sets which include only payoffrelevant information are known as Markov strategies. The assumption of Markov strategies implies that players are unable to observe events that happened in the deep past. The history of play is thus summarised through its effect upon the state variables.

When players' past actions are not directly observable, it is difficult to punish past deviations from the equilibrium. Effectively, the restriction to Markov strategies rules out the use of trigger strategies. The range of potential equilibria is therefore significantly narrowed.

While Markov strategies offer a way to limit the number of possible 
equilibria, they may not always be appropriate. For the Markovian restriction to be reasonable, players must be unlikely to use trigger strategies. In the regulation games studied here, we claim that players are unlikely to use trigger strategies. It seems implausible that a government would choose to punish a firm for deviations from the desired output level by taxing it for many periods in the future. When governments choose their tax rules, they enshrine them in legislation. The tax authority then applies the tax rule as specified in the legislation. Since the creation of the rule and its application are usually separate activities, taxation rules are unlikely to be reactionary. Governments also prefer to appear even-handed in their policies. A trigger strategy relies on the threat of harsh punishments to enforce an efficient equilibrium. Given that a deviation from the equilibrium output level is not illegal, it is unlikely that the government would wish to punish a firm for such a deviation. It is more reasonable to believe that the level of taxation will depend on the current state of the industry, but not upon the firms' history of actions. Thus, the use of Markov strategies in this thesis seems justified.

\subsection{Dynamic consistency}

\subsubsection{Dynamic consistency and precommitment}

The extension of game theory to dynamic games opened up a range of interesting new problems. Among those problems is the issue of dynamic consistency, which was first explored in the context of economic policy by Kydland and Prescott (1977). A plan is said to be dynamically consistent 
if a player has no incentive to deviate from it at any time in the future. Conversely, a dynamically inconsistent plan is one which, while optimal when conceived, the player will choose to deviate from in the future.

A dynamically inconsistent agent will be unable to adhere to an optimal plan without the aid of some precommitment device. Some of these devices are usually enforced by a third party. On a personal level, people rely on family members and friends to help them follow a chosen course of action; on a business level, the legal system enforces contractual commitments. However, precommitment power is harder to come by when there is no external 'enforcer' available. Governments, in particular, may find it very difficult to bind themselves, since any legislation that they pass can be overturned by future legislators. This thesis will examine the problem of a dynamically inconsistent regulator in some detail and propose a method by which a regulator can overcome their dynamic inconsistency.

\subsubsection{Time-consistency and perfection}

If precommitment is not possible, then an equilibrium involving dynamically inconsistent strategies is implausible. No agent will be willing to rely upon promises that they expect to be broken. Hence, strategies must be dynamically consistent to generate plausible equilibria. We now examine in greater detail precisely what is meant by dynamic consistency. There are two ideas of dynamic consistency that are relevant to this thesis: 'time-consistency' and 'subgame perfection'.

Time-consistency is the weaker of the two requirements. Any equilibrium that is not dynamically inconsistent is time consistent. Given that no 
agent has reneged in the past, and none are expected to renege in the future, no agent has an incentive to unilaterally renege on a time-consistent equilibrium.

A subgame perfect equilibrium must satisfy a more stringent test. subgame perfection requires that a strategy be optimal regardless of past deviations in either the state or in the other players' actions. This must be true for all possible values of the state variable and across all time periods. As such, a perfect strategy will usually depend on the state variable.

Open loop strategies are announced by agents at the beginning of the game, and so describe actions as functions of time and the initial state. Thus, a deviation from the expected path by any player will not change the actions dictated by an open loop strategy. This is likely to cause the open loop strategy to be sub-optimal in the periods following the deviation. Therefore, the player will have an incentive to deviate from it. It follows that the open loop strategy is not subgame perfect. Note that the strategy may still be time-consistent even if it is not dynamically inconsistent, as long as play remains on the equilibrium path.

In dynamic games, subgame perfection may be attained with statedependent, feedback strategies. Since perfection implies time-consistency (even though the converse is not true), a perfect feedback strategy will also be time consistent. Hence, time-consistent strategies can be either open loop or feedback. 


\subsubsection{Sufficient conditions for time-consistency}

Feedback strategies are designed to be optimal in all states. Thus, an equilibrium in feedback strategies is subgame perfect by construction. Open loop equilibria are rarely subgame perfect, but are often time-consistent along the equilibrium path. Bellman's Principle of Optimality states that the continuation of an optimal strategy is optimal in all states that arise from past optimal behaviour (Bellman, 1957). Thus, if the initial state is exogenously given, and players all choose optimal strategies, the resulting equilibrium will be time-consistent (Karp and Newbery, 1993).

The difficulty with this result is that it depends upon an exogenously specified initial state. If the initial state is not exogenous, then the current state must be a function of future actions. A variable whose value depends upon future events is known as a 'jump variable'. Problems with jump variables are not covered by the Principle of Optimality and rarely have time-consistent open loop solutions. However, the absence of a jump variable is sufficient to ensure time-consistency of an open loop equilibrium.

The intuition behind the above statement is fairly straightforward. The presence of a jump variable suggests that the current state and the current payoff depend upon expectations about the future. Thus, in period $t$, agents need to form expectations about actions and payoffs in period $t+n$, so that they can compute their optimal action. Time inconsistency can arise in two ways: first, if these expectations are not fulfilled then the period $t$ action becomes sub-optimal, and so the period $t+n$ action will be different from what was anticipated. Even if expectations are fulfilled, 
the period $t+n$ action is still likely to differ from the expected action. This is because the $t+n$ action has an effect upon the period $t$ payoff. Reoptimising in period $t+n$ would disregard the 'inter-temporal externality' on the previous periods' payoffs, since they are now sunk. Thus, in period $t+n$, the optimal action is unlikely to be the same as was expected in period $t$. As a result, the open loop equilibrium calculated in period $t$ will be time inconsistent.

Dynamic inconsistency is common in settings where governments regulate non-strategic but forward looking agents (Chari et al., 1988). When making decisions about the current period, such agents take future payoffs into consideration. If current payoffs are affected by future actions, then the problem of a subsequent regulator will differ from that of the current one. This implies that the regulator's optimal plan will change over time, and so the regulator will be dynamically inconsistent.

\subsubsection{Implications of dynamic inconsistency for regulation}

The problem considered in this thesis will exhibit dynamic inconsistency due to the presence of a jump variable in the regulator's objective function. As a result of this, the regulator is unable to obtain the first-best price path. In the subsequent chapters, we will focus on this inefficiency. But before describing the specifics of the model, it is worth canvassing the likely consequences for a dynamically inconsistent regulator. Note that the assumptions in the following paragraphs are made purely for exposition purposes. All assumptions underlying the formal model will be explicitly stated in chapter 3. 
Imagine that the regulator's objective function includes a jump variable. That is, welfare depends upon the regulator's future actions. In each period, the regulator chooses the rate of a tax that is imposed on a polluter. If the tax rate is expected to fall in the next period, the polluter will inter-temporally substitute away from current production towards future production; hence, production in the current period will decrease. Suppose that the fall in the current period's profits and consumer surplus outweighs the decrease in pollution. Then the current period's welfare will decrease. To prevent this, the regulator must commit to setting high taxes in future periods. The expectation of high future taxes would remove the incentive of the polluter for inter-temporal substitution. However, once these future periods arrive, the regulator will no longer be concerned with the effect of his tax choice upon past welfare. Thus, the regulator would revise the tax downward if they have the opportunity to do that.

A sophisticated regulator will anticipate future temptations to decrease taxes. If they are unable to commit to future policies, they will set the current tax strategically to counter future incentives for tax reductions. They achieve that by setting a low current tax rate. The essence of the problem is that the polluter is under-producing in the current period, relative to the future period. This problem can be corrected by decreasing current taxation to remove the incentive to shift production to the future. As a result, a sophisticated regulator who is unable to precommit will under-tax the polluter relative to the social optimum.

Under-taxation of a polluter implies over-pollution. Since pollution and its consequences are some of the most pressing problems facing modern industrialised societies, designing an effective mechanism to control it 
is a problem of great importance. Correcting a potential policy flaw that could lead to significant over-pollution is far more than an academic exercise.

\subsection{Causes of regulatory dynamic inconsistency}

\subsubsection{Inconsistency of the welfare function}

A regulator's welfare function consists of four components: firms' profits, consumer surplus, externalities and government revenue. For now, revenues will be ignored. We abstract from them in order to focus on corrective, rather than revenue gathering, regulation.

In a regulated industry that exhibits dynamic inconsistency, firms' profits will often contain a jump variable. It is also possible that consumer surplus may contain a jump variable, provided that the inconsistency in the industry is caused by demand-side behaviour. Jump variables in either of these functions can cause the regulator's welfare function to exhibit inconsistency.

Note that inconsistency in the profit function will not always be transferred to welfare: if the jump variable is in the inverse demand function alone, and firms' revenues are simply a transfer from consumers to firms, then the jump variable will not appear in welfare. However, this will not be true if the regulator weighs profits and consumer surplus differently. In this case, expectations about future variables will still be present in the welfare function and the regulator will be inconsistent. 


\subsubsection{Industries in which dynamic inconsistency arises}

There are numerous examples of industries where dynamic inconsistency arises from a jump variable in a firm's profit function. Most commonly, it is found where durable or addictive goods are being produced, or where an exhaustible resource is being extracted.

\section{Exhaustible resources}

Economists have been interested in exhaustible resources since Harold Hotelling's seminal paper (Hotelling, 1931). In this paper, Hotelling shows that the pricing of an exhaustible resource depends upon expectations of subsequent prices. This dependence upon future decisions introduces a jump variable the profits of firms who utilise the resource. In particular, Karp and Newbery (1993) show that a firm with monopsony power who purchases an exhaustible resource will be dynamically inconsistent if they face either a competitive fringe of consumers, or increasing extraction costs.

\section{Addictive goods}

The theory of rational addiction suggests that an addictive good can be modelled as a commodity whose current consumption increases the marginal benefit of future consumption (Becker and Murphy, 1988). If expected future prices are low, then consumption is affected in two ways. First, expected future consumption will rise as a direct result of the lower expected price. Secondly, current consumption will rise as consumers attempt to increase the benefits that they will reap from the low future prices. Thus, 
a firm selling an addictive good can affect current demand by manipulating expectations about its future pricing strategy. This introduces a jump variable into the firm's profit function and causes the firm to act in a dynamically inconsistent fashion.

\section{Durable goods}

A durable good is one which is not consumed instantly, but continues to provide value for an extended period of time. When an individual decides to purchase a durable good they must weigh the benefit of purchasing in the current period against possible price reductions if they delay purchase until a later period. A firm selling durable goods, like a firm selling addictive goods, can influence the current period's profit by manipulating consumers' expectations about future prices. A high expected future price will induce more consumers to buy in the current period. The future price is a jump variable in the firm's profit function and induces dynamic inconsistency. 


\section{Chapter 3}

\section{Problem}

The problem of regulating a dynamically inconsistent polluter is complicated: a regulator seeking to maximise social welfare will have to take into account the dynamic structure of consumer demand for the polluter's product. This implies that instantaneous welfare will contain a jump variable and hence the polluter's time consistency problem will be transferred to the regulator. In the absence of precommitment devices a regulator faced with a dynamically inconsistent polluter may be unable to attain the first-best outcome. A likely consequence of this failure is over-pollution.

This chapter presents a model of a polluting durable goods monopoly and shows how its regulation may be subject to time inconsistency. We will characterise both the first-best (precommitment) and the second-best (time-consistent) regulatory outcomes. They will then be used as benchmarks for the proposed taxation mechanism in the next chapter. 


\subsection{A model of a dynamically inconsistent regu- lator}

In each situation described in section 2.3.2, a regulator will be affected by the dynamic inconsistency of the regulated firm. In this chapter we set up a model to illustrate the problem. We will focus on the specific case of a durable goods producer, which will serve to illustrate how our proposal can overcome the regulatory problems induced by jump states.

In this section we elucidate the model and describe the players' decisions and interactions. The main decision makers are a regulator and a monopolist who supplies an infinitely durable good to a mass of consumers. We consider a durable goods producer because their behaviour is known to produce dynamic inconsistency (see section 2.3.2).

\subsubsection{The consumption decision}

The monopolist produces an infinitely durable good, which is then supplied to a mass of consumers. For simplicity this mass is normalised to 1 . The period- $t$ price is denoted by $p^{t}$. Each consumer can buy only one unit of the good in their lifetime. After the purchase they withdraw from the market, but continue to enjoy a stream of benefits $v \in[0,1]$ in perpetuity. Future benefits are discounted by a factor $\beta{ }^{1}$

The taste parameter, $v$, indicates an individual consumer's valuation of the good. Consumers are assumed to have heterogeneous valuations and their tastes are distributed across the population according to a probabil-

\footnotetext{
${ }^{1}$ The parameter $\beta$ can also capture depreciation of the benefits of the durable good.
} 
ity density function $\phi(v)$, which has a corresponding cumulative density function (CDF) denoted by $\Phi(v)$. We assume that $\phi(v)$ is everywhere positive.

\section{Price trajectory}

Consumers decide the timing of their purchases. Those who are most eager will be willing to pay a premium to buy the good early on. Hence, initially the price of the good will be high. As the early adopters leave the market the price of the good will be reduced in order to entice the remaining consumers to make a purchase. Consequently, the equilibrium price path will be decreasing over time.

It must be noted that it may not be optimal for the monopolist to operate in all periods. As Stokey originally showed, a monopolist with constant marginal costs and precommitment power will choose to produce only in the first period (Coase, 1972; Stokey, 1981). Two key features of the model studied here distinguish it from Stokey's:

1. the monopolist does not have precommitment power; and,

2. the monopolist has convex costs (assumption 2).

As shown by Kahn (1986), the presence of either of these properties invalidates Stokey's result. Convexity of costs implies that higher production will increase marginal costs, and thus it induces the monopolist to smooth production over time costs. Kahn shows that, in an infinite horizon setting, the monopolist's production smoothing will cause them to asymptotically approach a steady-state price. Thus, the good's price sequence is Cauchy and converges to a limit (i.e. a steady state price) as 
$t \rightarrow \infty:$

$$
p^{t-1}-p^{t} \geq p^{t}-p^{t+1} \quad \forall t
$$

This dynamic stability condition constrains the price trajectory in the market under consideration.

\section{Consumers' intertemporal trade-offs}

In a durable goods market the consumer's main decision is when to purchase. Knowing that the price will decline over time, they weigh the benefit of purchasing in the current period against the expected price reduction of the subsequent period. If the expected cost reduction from waiting until the next period outweighs the foregone $v$, they will delay purchase.

The lifetime net benefit, $V^{t}$, of purchasing in period- $t$ is the net present value of the stream of discounted benefits, minus the cost of purchase:

$$
V^{t}=\frac{v}{1-\beta}-p^{t}
$$

Similarly,

$$
V^{t+1}=\frac{\beta v}{1-\beta}-\beta p_{e}^{t+1}
$$

where $p_{e}^{t+1}$ is the anticipated future price. Thus, purchase will be delayed in period- $t$ if

$$
V^{t+1}>V^{t}
$$

Substituting (3.2) and (3.3) in to (3.4) gives

$$
v<p^{t}-\beta p_{e}^{t+1}
$$

By shifting equations (3.3) and (3.2) back one period and performing a similar rearrangement, one finds that purchase will be delayed in period- 
$t-1$ if

$$
v<p^{t-1}-\beta p^{t}
$$

Suppose that consumers have rational expectations: $p_{e}^{t+1}=p^{t}$. Then a consumer who chooses not to delay purchase in the current period will never prefer to consume in a later period. This can be seen by combining equation (3.1) with $\beta<1$ and shifting it forward one period to give $p^{t}-$ $p^{t+1}>\beta\left(p^{t+1}-p^{t+2}\right)$, which rearranges to

$$
p^{t}-\beta p^{t+1}>p^{t+1}-\beta p^{t+2}
$$

Equation (3.4) implies that all consumers who choose to buy in the current period have tastes such that $v \geq p^{t}-\beta p_{e}^{t+1}$. Hence,

$$
v \geq p^{t}-\beta p^{t+1}>p^{t+1}-\beta p^{t+2}>\ldots>p^{T-1}-\beta p^{T}, \quad \forall T>t,
$$

and each consumer who buys the good in period- $t$ will be worse off delaying the purchase to any future period.

\section{The demand function}

The above discussion of consumer behaviour enables us to obtain the demand function for a given period $t$. Current demand is the mass of people who chose to delay purchase in the previous period but choose not to delay from the current period to the next. Combining the equations describing consumer choice with the CDF of $v$ gives us the mass of consumers who purchase in period $t$. The resulting demand is

$$
x^{t}=x\left(p^{t-1}, p^{t}, p_{e}^{t+1}\right)= \begin{cases}\Phi\left(p^{t-1}-\beta p^{t}\right)-\Phi\left(p^{t}-\beta p_{e}^{t+1}\right) & \text { if } t>0 \\ 1-\Phi\left(p^{0}-\beta p_{e}^{1}\right) & \text { if } t=0\end{cases}
$$


Since the function $\Phi(\cdot)$ is a CDF, it must be increasing. Equation (3.7) implies that $\Phi\left(p^{t-1}-\beta p^{t}\right)>\Phi\left(p^{t}-\beta p_{e}^{t+1}\right)$, so demand will be positive in all periods. Furthermore, we require that the demand function to be concave in both the current and future prices. This, along with Assumption $2-$ introduced in section 3.1.2 - will guarantee the concavity of profits. ${ }^{2}$

Assumption 1. The demand function function, $x^{t}$, satisfies $\frac{\partial^{2} x^{t}}{\partial\left(p^{t}\right)^{2}} \leq 0$, $\frac{\partial^{2} x^{t}}{\partial\left(p_{e}^{t+1}\right)^{2}} \leq 0$.

\subsubsection{The production decision}

Suppose that the monopolist incurs operating costs $C\left(x^{t}\right)$. Thus, his profit function is

$$
\pi^{t}=\pi\left(p^{t-1}, p^{t}, p_{e}^{t+1}\right)=p^{t} x\left(p^{t-1}, p^{t}, p_{e}^{t+1}\right)-C\left(x\left(p^{t-1}, p^{t}, p_{e}^{t+1}\right)\right)
$$

To ensure concavity of instantaneous profits, it is necessary to assume convexity of the cost function. As discussed above, this also implies that a monopolist who is able to precommit will not cease production after the first period (Kahn, 1986).

Assumption 2. The monopolist's cost function satisfies $C^{\prime \prime}\left(x^{t}\right)>0$.

Along with Assumption 1 this assumption guarantees that profits will be concave in both the present price and next period's price: $\frac{\partial^{2} \pi^{t}}{\partial\left(p^{t}\right)^{2}} \leq 0$, $\frac{\partial^{2} \pi^{t}}{\partial\left(p_{e}^{t+1}\right)^{2}} \leq 0$. See Appendix A for a proof.

\footnotetext{
${ }^{2}$ Note that these conditions are sufficient for concavity. We do not demonstrate that they are necessary.
} 


\subsubsection{The regulator's decision}

We assume that the regulator seeks to maximise social welfare. They take in to account the monopolist's profit, the consumer surplus, and potential externalities arising from production. In the partial equilibrium model studied here, the consumer surplus considered is solely the net benefit gained by consumers from purchasing the monopolist's good. The partial equilibrium nature of this model makes it difficult to speak accurately of welfare but we use it as a convenient approximation, having noted that this is not a true welfare analysis. Consumer surplus is given by

$$
\begin{aligned}
C S^{t} & =C S\left(p^{t-1}, p^{t}, p_{e}^{t+1}\right) \\
& =\int_{p^{t}-\beta p_{e}^{t+1}}^{p^{t-1}-\beta p^{t}} \phi(v)\left(v-p^{t}\right) d v+\int_{p^{t-1}-\beta p^{t}}^{1} \phi(v) v d v \\
& =E\left(v-p^{t} \mid p^{t}-\beta p_{e}^{t+1} \leq v<p^{t-1}-\beta p^{t}\right)+E\left(v \mid v \geq p^{t-1}-\beta p^{t}\right) .
\end{aligned}
$$

In addition to consumer surplus and profits, the regulator must also consider the environmental impact of pollution generated by production. Our setting assumes that pollution is a flow, rather than a stock, externality. That is, instead of modelling pollution as a stock of harm that accumulates over time, we consider harm that is caused by the polluter's current production. In other words, we assume that the level of emissions is an increasing function, $\psi\left(x^{t}\right)$, of current output. Specifically, the pollution function satisfies the following condition.

Assumption 3. The pollution function satisfies $\psi^{\prime}\left(x^{t}\right)>0$ and $\psi(0)=0$.

Such an assumption is plausible for some, but not all, types of pollution. Some pollutants are quickly dispersed and may have little time to 
accumulate. Thus, it can be reasonably modelled as a flow externality. Examples of these are particulate emissions and volatile organic compounds. Heavy metals and greenhouse gasses, in contrast, can accumulate in the soil and eventually reach harmful levels. It would be more suitable to consider them as stock pollutants. Either approach is valid for a subset of pollution problems. We have chosen flow pollution because the framework facilitates simple analysis of time inconsistent regulation.

Our assumptions yield the following instantaneous welfare function:

$$
\begin{aligned}
w^{t} & =w\left(p^{t-1}, p^{t}, p_{e}^{t+1}\right) \\
& =C S\left(p^{t-1}, p^{t}, p_{e}^{t+1}\right)+\pi\left(p^{t-1}, p^{t}, p_{e}^{t+1}\right)-\psi\left(x\left(p^{t-1}, p^{t}, p_{e}^{t+1}\right)\right) \\
& =\int_{p^{t}-\beta p_{e}^{t+1}}^{1} \phi(v) v d v-C\left(x\left(p^{t-1}, p^{t}, p_{e}^{t+1}\right)\right)-\psi\left(x\left(p^{t-1}, p^{t}, p_{e}^{t+1}\right)\right) .
\end{aligned}
$$

Given rational expectations $\left(p_{e}^{t+1}=p^{t}\right)$, the above definition implies the presence of a jump variable in the regulator's objective function. As argued in section 2.2.3 this may cause a time consistency problem for the regulator.

\subsection{Laissez-faire performance}

Having described the agents in the market and their interactions, we now turn to the topic of efficiency. It could be that this market is already efficient. It is also possible that the regulator may not be able to improve on the free market outcome. The first step in assessing any government intervention is to characterise the performance of the unregulated market. Then in section 3.3.2 we will compare the laissez faire outcome to the regulator's benchmark pricing policies. 


\subsubsection{The monopolist's price path}

As already established, the monopolist's demand function is

$$
x^{t}=\Phi\left(p^{t-1}-\beta p^{t}\right)-\Phi\left(p^{t}-\beta p_{e}^{t+1}\right) .
$$

It generates the following instantaneous profit function:

$$
\begin{aligned}
\pi\left(p^{t-1}, p^{t}, p_{e}^{t+1}\right)=p^{t}\left[\Phi \left(p^{t-1}\right.\right. & \left.\left.-\beta p^{t}\right)-\Phi\left(p^{t}-\beta p_{e}^{t+1}\right)\right] \\
& -C\left(\Phi\left(p^{t-1}-\beta p^{t}\right)-\Phi\left(p^{t}-\beta p_{e}^{t+1}\right)\right)
\end{aligned}
$$

The monopolist's objective is maximization of lifetime profits. Suppose that his discount factor is $\delta$. To get an interior equilibrium, we assume that $\beta<\delta<1$.

The presence of a jump state, $p_{e}^{t+1}$, suggests that profit maximization will give rise to a time inconsistency problem for the monopolist. This problem can be conceptualised as a strategic conflict between the monopolist's current and future 'selves'. We will model the time consistent sequence of decisions as the subgame perfect equilibrium outcome of a dynamic 'intrapersonal' game. This game is played by different agents, each a temporal incarnation of the monopolist associated with a particular time period. These temporal 'selves' choose prices to maximise their payoffs while accounting for the discrepancy between their interests and those of future agents. In that our agents are 'sophisticated' in the sense of O’Donoghue and Rabin (2001).

Our analysis will focus on a particular type of subgame perfect equilibrium. Namely, we consider the Markov-perfect equilibrium of the monopolist's intrapersonal game. This solution concept restricts the players' strategies to be functions of the current state: $p^{t}=g\left(p^{t-1}\right)$. The Markovian 
approach allows us to use dynamic programming techniques to characterise the equilibrium. It assumes away history-dependent punishments with trigger strategies.

Furthermore, we need to specify how current agents form expectations about the behaviour of future players. Stokey (1981) shows that rational expectations are not sufficient to prevent a multiplicity of equilibria similar to that of the Folk Theorem. To avoid this multiplicity, we assume that decision makers have perfect rational expectations. That is, we require expectations of future prices to be correct both on and off the equilibrium path. The restriction to Markovian strategies and perfect rational expectations imply that $p_{e}^{t+1}=g\left(p^{t}\right)$.

If the monopolist does not have precommitment power and follows a Markov strategy $g(p)$, then his optimal decision rule must solve the Bellman equation

$$
\Pi\left(p^{t-1}\right)=\max _{p^{t}}\left\{\pi\left(p^{t-1}, p^{t}, g\left(p^{t}\right)\right)+\delta \Pi\left(p^{t}\right)\right\} .
$$

This equation recursively defines each player's lifetime payoff, as captured by the value function $\Pi(p)$, in terms of future players' lifetime payoffs. That is, the current player's equilibrium lifetime payoff is the maximised value of his instantaneous payoff from his decision, plus the anticipated continuation payoff of tomorrow's decision. Furthermore, the optimal pricing strategy is time invariant, implying that

$$
g\left(p^{t-1}\right)=\arg \max _{p^{t}}\left\{\pi\left(p^{t-1}, p^{t}, g\left(p^{t}\right)\right)+\delta \Pi\left(p^{t}\right)\right\} .
$$

In Appendix B we use dynamic programming techniques to characterise the Markov-perfect equilibrium. Differentiation yields a first-order 
condition and an envelope condition. Combining these delivers a generalised Euler-Lagrange equation

$$
\pi_{2}^{t}+\pi_{3}^{t} g_{1}^{t+1}+\delta \pi_{1}^{t+1}=0
$$

where the subscript $i$ denotes the partial derivative with respect to the function's $i$-th argument. ${ }^{3}$ This difference-differential equation implicitly characterises the price path that will be chosen in equilibrium. The first term of this equation reflects the direct effect of $p^{t}$ on the profit function. The second term encapsulates the effect of $p^{t}$ on $\pi^{t}$ via the strategy choice, $g\left(p^{t}\right)$, of the subsequent agent. The final term captures the discounted effect of the current action on future profits. Optimality requires that these effects sum to 0 .

\subsubsection{Inefficiency of the laissez-faire outcome}

Next we investigate whether the laissez-faire price path derived in section 3.2.1 provides a rationale for government intervention. The definitive answer to this question requires characterising the regulatory equilibrium. Intuitively, our setting exhibits a number of inefficiencies which suggest that regulation may improve welfare. First, the market is served by a monopolist. When a producer has market power, he usually tends produce too little and charge a price above the efficient level. Second, production causes a negative externality as pollution is released. Such externalities may imply overproduction relative to the first-best outcome. Finally, the monopolist's profit function contains a jump variable. Section 2.2.3 showed how this may create a time consistency problem for the producer.

\footnotetext{
${ }^{3}$ For example, $\pi_{2}^{t}=\partial \pi\left(p^{t-1}, p^{t}, p^{t+1}\right) / \partial p^{t}$.
} 
This problem may induce the monopolist to increase production, further exacerbating potential overprovision of the durable good.

The three welfare effects mentioned above act in different directions. Monopoly power pushes the price above efficiency. Conversely, pollution and the monopolist's time consistency problem tend to reduce the price below the efficient level. We cannot predict the net effect without knowledge of market specifics. It may even be possible for the three inefficiencies to exactly cancel each other out. However, as section 3.3.2 discusses, it is unlikely that the laissez-faire price will replicate the efficient path. Since we do not exclude the possibility of a negative tax (i.e. a subsidy), there is no need to assume that a particular type of inefficiency is dominant. The proposal described in Chapter 4 will still yield the first-best outcome.

\subsection{Benchmarking regulatory performance}

To evaluate the regulatory intervention proposed in Chapter 4, we first need to study the price paths attainable by a regulator. For the purpose of benchmarking we assume that in each period the regulator has direct control the price of the durable good. Such equilibria would arise in standard models of Pigouvian taxation (Benchekroun and Long, 1997).

This section characterises two benchmark plans,

1. the first-best price path where the regulator can commit to future prices; and,

2. the second-best price path where the regulator is unable to commit to future prices. 


\subsubsection{First-best price plan}

\section{Deriving the plan}

The regulator's first-best price path is the plan he would choose in the first period if at that time he could precommit to a complete sequence of future prices. Given rational expectations, $\left(p_{e}^{t+1}=p^{t+1}\right)$, this plan can be obtained as the open-loop Nash equilibrium (OLNE) of the problem

$$
\max _{\mathbf{p}^{t}} \sum_{t=1}^{\infty} \delta^{t-1} w^{t}\left(p^{t-1}, p^{t}, p^{t+1}\right),
$$

where $\mathbf{p}^{t}$ is the price vector $\mathbf{p}^{t}=\left\{p^{t}\right\}_{t=1}^{\infty}$. The solution to this problem is a sequence of prices, indexed by time, that maximises the net present value of total welfare.

The optimal precommitment price path, $\mathbf{p}^{t}$, satisfies the first-order conditions

$$
\begin{aligned}
& w_{2}^{t}+\delta w_{1}^{t+1}=0, t=1 \\
& w_{3}^{t-1}+\delta w_{2}^{t}+\delta^{2} w_{1}^{t+1}=0, \quad t \geq 2 .
\end{aligned}
$$

The above equations are obtained by differentiating period-1 lifetime welfare with respect to the period-1 price $p^{1}$ and an arbitrary future price $p^{t}$, $t>1$. Since these prices solve an unconstrained maximisation problem, they attain the highest possible net present value of welfare.

Substituting the derivatives of instantaneous welfare (3.14) into (3.23) and (3.24) yields equivalent conditions expressed in terms of monopoly 
profit, consumer surplus and pollution costs.

$$
\begin{array}{r}
\pi_{2}^{t}+C S_{1}^{t}-\psi_{2}^{t}+\delta\left[\pi_{1}^{t+1}+C S_{1}^{t+1}-\psi_{1}^{t+1}\right]=0 \\
\pi_{3}^{t-1}+C S_{3}^{t-1}-\psi_{3}^{t-1}+\delta\left[\pi_{2}^{t}+C S_{2}^{t}-\psi_{2}^{t}\right]+\delta^{2}\left[\pi_{1}^{t+1}+C S_{1}^{t+1}-\psi_{1}^{t+1}\right]=0
\end{array}
$$

\section{Dynamic inconsistency of the first-best plan}

As already argued, the presence of a jump variable in the instantaneous welfare function will likely give rise to a time consistency problem for the regulator. It would cause the social planner to change their price plan if they could re-optimise in a future period. To see this, suppose that currently the regulator follows the plan prescribed by condition (3.24). If, however, they were able to deviate from that plan, they would choose their current price according to (3.23), rather than (3.24).

Mathematically, time inconsistency arises from the presence of the term $w_{3}^{t-1}$ in condition (3.24). This term captures the effect of a change in the current period's price on the previous period's welfare. This effect will be internalised by a regulator who can precommit to future prices. However, if a subsequent regulator can re-optimise, he will disregard periods that, from his viewpoint, have already passed. Consequently the re-optimised price path will be revised downward, drawing too much demand away from the preceding period.

Unless the social planner has access to a precommitment device that enables him to enforce the plan defined by (3.23) and (3.24), he will not be able to attain the first-best outcome because of his incentive to deviate 
from it in future periods. When choosing his pricing strategy, a sophisticated social planner will recognise this problem and account for future incentives to deviate. The subgame perfect equilibrium of the intrapersonal game between the current and regulators will deliver a time consistent sequence of prices.

\subsubsection{Second-best price path}

A regulator who is sophisticated (in the sense of O'Donoghue and Rabin (1999)) will take into account the behaviour of their future selves and will choose the current price accordingly. That is why we now consider a dynamic intrapersonal game, where the players are the various temporal incarnations of the social planner. Essentially the current regulator solves a constrained maximisation problem where future pricing policies are required to be sub-game perfect. Again, we focus on the Markovperfect equilibrium of the regulator's intrapersonal game: the current pricing strategy is assumed to depend only on the current state of the world: $p^{t}=f\left(p^{t-1}\right)$. Furthermore, we assume that the strategy function $f(p)$ is continuously differentiable, which eliminates the possibility of an infinite number of equilibria. However, the above assumptions do not guarantee existence or uniqueness of a Markov-perfect equilibrium.

Again, we need to specify how the regulator forms their expectations about future prices. As before, we assume that the social planner has perfectly rational expectations. That is, he correctly predicts future prices on and off the equilibrium path. This assumption prevents the existence of a multiplicity of equilibria (Stokey, 1981). Given the focus on Markovian 
strategies it implies that $p^{t+1}=f\left(p^{t}\right)$.

The regulator's MPE price path can be characterised with the help of dynamic programming. The equilibrium pricing strategy solves the Bellman equation:

$$
W\left(p^{t-1}\right)=\max _{p^{t}}\left\{w\left(p^{t-1}, p^{t}, f_{e}\left(p^{t}\right)\right)+\delta W\left(p^{t}\right)\right\} \quad \forall: t \geq 1,
$$

where $W(p)$ is the social planner's value function. Since MPE strategies are time invariant, we must also have

$$
f\left(p^{t-1}\right)=\arg \max _{p^{t}}\left\{w\left(p^{t-1}, p^{t}, f_{e}\left(p^{t}\right)\right)+\delta W\left(p^{t}\right)\right\} .
$$

The recursive formulation of this problem ensures the regulator's pricing policy will be time consistent.

Suppose that Assumptions 1 and 2 are satisfied. Then the method used to derive the monopolist's Euler equation can also yield the generalised Euler-Lagrange equation of the welfare maximisation game:

$$
w_{2}^{t}+w_{3}^{t} f_{1}^{t+1}+\delta w_{1}^{t+1}=0
$$

This equation implicitly defines the second-best price trajectory that would result from adhering to the time consistent policy function $f(p)$. The term $w_{3}^{t} f_{1}^{t+1}$ reflects the intrapersonal strategic effect, i.e. the effect of current prices on current welfare via future pricing. When the period$t+1$ price is determined, the regulator will not take into account the negative effect of this pricing decision on period- $t$ welfare. Thus, from the current viewpoint, future prices are expected to be suboptimally low. The period- $t$ regulator anticipates this behaviour and mitigates these effects by choosing lower current prices. This implies that the time consistent prices 
described by equation (3.29) will be below the first-best precommitment prices, thus generating lower welfare.

Using the definition of instantaneous welfare, equation (3.29) can be rewritten as

$$
\begin{aligned}
& (\underbrace{\pi_{2}^{t}+f_{1}^{t+1} \pi_{3}^{t}+\delta \pi_{1}^{t+1}}_{\text {laissez-faire Euler eqn }})+(\underbrace{C S_{2}^{t}+f_{1}^{t+1} C S_{3}^{t}}_{\text {effect of } p \text { on } C S}) \\
& -(\underbrace{\psi_{2}^{t}+f_{1}^{t+1} \psi_{3}^{t}+\delta \psi_{1}^{t+1}}_{\text {effect of } p \text { on pollution }})=0
\end{aligned}
$$

or, alternatively,

$$
\underbrace{\left[\pi_{2}^{t}+C S_{2}^{t}-\psi_{2}^{t}\right]}_{\text {direct effect }}+\underbrace{f^{t+1}\left[\pi_{3}^{t}+C S_{3}^{t}-\psi_{3}^{t}\right]}_{\begin{array}{c}
\text { indirect effect of } p^{t} \\
\text { on present via } f^{t+1}
\end{array}}+\underbrace{\delta\left[\pi_{1}^{t+1}-\psi_{1}^{t+1}\right]}_{\begin{array}{c}
\text { discounted, direct effect } \\
\text { of } p^{t} \text { on the future }
\end{array}}=0 .
$$

Note that, if

$$
C S_{2}^{t}+f_{1}^{t+1} C S_{3}^{t}=\psi_{2}^{t}+f_{1}^{t+1} \psi_{3}^{t}+\delta \psi_{1}^{t+1},
$$

then the time consistent laissez-faire price path could replicate the regulator's second-best price path. That is to say, if the downward pressure on the price from the reduction in market power is precisely offset by the upward pressure from the pollution externality, the laissez-faire outcome will be efficient. Of course, this coincidence is highly unlikely. It should also be noted that, if the regulator is unable to precommit, social welfare could possibly be higher in the absence of government intervention.

We conclude that the social planner's optimal time-consistent price sequence is not first best. The dynamic consistency problem experienced by the regulator prevents them from fully correcting the inefficiencies associated with the pollution emissions of a durable goods monopolist. 


\section{Chapter 4}

\section{Proposition}

The previous section demonstrated that if there is a jump variable in firm profits and if the regulator cannot precommit to future prices, he is unable to follow the first-best price path. That is because the polluter's time consistency problem is transferred to the regulator. In order to maintain time consistency of his policies, the regulator can only implement a second best outcome. The first-best level of welfare is feasible only if the government could credibly precommit to future actions.

The problem of gaining commitment power, where it is not obviously available, has been explored in the literature on strategic delegation. In this chapter we study how the idea of strategic delegation has been used in the context of duopoly games to avail agents of precommitment power. We then combine the concept of strategic delegation with Pigouvian taxation to create a taxation mechanism that overcomes the regulator's time consistency problem. 


\subsection{Strategic delegation}

The strategic delegation literature claims that the separation of ownership and management can be used as a means of gaining a strategic advantage in imperfectly competitive markets. Oligopolists who compete in a Cournot setting would each like to be in the position of a Stackelberg leader. By delegating output decisions, they can use managerial contracts to gain a first-mover advantage. If the owners can set the managerial wage contracts before output decisions are made, they can provide their managers with incentives for aggressive production. Thus, wage contracts can have commitment power: delegation will provide firms with a first-mover advantage.

The idea of strategic delegation began with the papers of Sklivas (1987) and Fershtman and Judd (1987), in which they suggest that each duopolist could increase their profits by delegating output decisions to a manager. The manager's behaviour is incentivised through a remuneration contract. The papers show that the decision to delegate managerial control is individually rational and a dominant strategy for each firm. This line of work has been continued by many authors, including Miller and Pazgal (2001), Basu (1993) and Baye et al. (1996).

In a different strand of research, Rogoff (1985) shows that a government too can benefit from the precommitment power of delegation. $\mathrm{He}$ studies a macroeconomic model of monetary policy. Agents' rational expectations imply the presence of jump states in welfare, giving rise to a time consistency problem for the government. Thus, in the absence of precommitment, the government's monetary policy decisions tend to ex- 
hibit inflationary bias. Rogoff argues that the appointment of a central banker with a particular set of preferences would allow the government to credibly commit to socially optimal inflation However, such one-shot delegation would require the regulator to find a third party whose preferences are socially optimal. The difficulties this entails are obvious, so such a solution cannot be considered a practical.

Similarly, we argue that 'delegation' could provide the government with the necessary precommitment power to achieve the first-best outcome when regulating a durable goods monopolist. We combine the approaches of Rogoff (1985) and Sklivas (1987). In our model, pricing decisions are 'delegated' to the monopolist, while the regulator uses pecuniary incentives to influence future prices. The monopolist is induced to follow the regulator's preferred price path with the help of a taxation mechanism. The purpose of the tax is to provide the producer with socially optimal incentives. Our contribution is to show that taxes not only redress the inefficiencies arising from pollution and market power, but also serve as a commitment device by decoupling the regulator's decision from the pricing decision.

\subsection{Optimal taxation}

Using a delegation tax game to overcome dynamic inconsistency has three key advantages over Rogoff's one-shot delegation approach:

Ease of implementation Taxation is a type of regulation that is already performed by the government and so the institutions are already in 
place to implement this policy. The regulator only needs to adjust the tax rule to ensure time-consistent implementation.

Dynamic robustness A regulator who has a time consistency problem will have an incentive to intervene in the future if they are not insulated from the pricing decision. We show that our proposal attains the first-best outcome even when the government is able to alter the taxation policy in future periods.

Insensitivity to managerial preferences In contrast to the approach taken by Rogoff, our model does not require delegation to a party with a particular set of preferences. Pricing decisions are made by the monopolist themselves and the taxation mechanism will provide them with correct incentives regardless of their demand and cost structure.

\subsubsection{A regulatory model}

We now extend the model described in the previous chapter to include a taxation mechanism and show how it overcomes the regulator's time inconsistency problem.

To maximise social welfare, the social planner must eliminate the inefficiencies generated by the pollution externality, the market power and the dynamic inconsistency of the monopolist. The government can motivate him to follow the socially optimal price path by using Pigouvian taxes that increase firm costs. Rather than directly choosing prices, the social planner now maximises welfare by choosing a tax policy. The timing of the taxation game discussed below implies that the regulator cannot affect the current choice. This enables him to resolve his time inconsistency 
problem.

\section{Pigouvian taxes}

In this model we consider a flow pollution externality $\psi\left(x^{t}\right)$. The Pigouvian tax could be levied on either output or pollution. We assume that the government taxes emissions, but our results would be similar if output was taxed instead. Thus, the monopolist's period- $t$ tax obligation can be written as

$$
\Omega^{t}=\tau^{t} \psi\left(x^{t}\right)
$$

Note that $\tau^{t}$ might vary over time. In our model, this would happen if the value of the state variable changes throughout the game.

The monopolist's instantaneous profit, net of taxes, is given by

$$
\pi^{t}\left(p^{t-1}, p^{t}, p^{t+1}, \tau^{t}\right)=p^{t} x^{t}-C\left(x^{t}\right)-\tau^{t} \psi\left(x^{t}\right) .
$$

\section{Tax revenues}

The tax revenue raised by the government is defined as the sum paid by the monopolist. However, the regulator's valuation of this revenue may not be the same as its monetary value. To recognise that the government and the monopolist may value tax revenues differently, we assume that the welfare benefit from the tax revenues is $\alpha \tau^{t} \psi\left(x^{t}\right), \quad \alpha \in[0,1]$. If $\alpha=0$ tax revenues have no social benefit, while $\alpha=1$ indicates that the government and the monopolist value the revenue equally.

We do not hypothesise what might be done with the tax revenues since they may not remain within the industry. However, in order to remain revenue-neutral, they could be returned to the monopolist as a lump-sum 
transfer. Provided that the transfer is not dependent upon the monopolist's actions, they would not have an impact on the price path chosen or the efficiency of the market.

\section{Costs to policy adjustment}

In many real-world situations, government policy changes are not costless. There could be costs to changing the tax regime in the consultation, policy development and political manoeuvring that must be done. Analytically this implies that previous tax policies may affect current welfare. Consequently, $\tau^{t-1}$ would be a payoff-relevant state variable in period $t$.

We assume that the larger the deviation from the status quo, the larger the welfare cost. To model this consideration, we include the term

$$
\theta\left(\tau^{t}-\tau^{t-1}\right)^{2}
$$

in period- $t$ instantaneous welfare. That is, the cost of changing the tax rate increases proportionately to the square of the change. ${ }^{1}$ This specification ensures that the adjustment cost is positive. Moreover, it reflects the difficulty of enacting significant changes in regulations. The coefficient $\theta$ allows us to capture the importance of these costs relative to consumer surplus and profits.

\footnotetext{
${ }^{1}$ Any convex function would suffice but the use of a quadratic function simplifies the derivations with little loss of generality since the functional form is not central to the proposed mechanism.
} 
The regulator's instantaneous payoff is thus

$$
\begin{gathered}
w^{t}\left(p^{t-1}, p^{t}, p^{t+1}, \tau^{t-1}, \tau^{t}\right)=\underbrace{\pi^{t}\left(p^{t-1}, p^{t}, p^{t+1}\right)}_{\text {Gross profits }}+\underbrace{C S^{t}\left(p^{t-1}, p^{t}, p^{t+1}\right)}_{\begin{array}{c}
\text { Consumer } \\
\text { surplus }
\end{array}} \\
-\underbrace{\psi^{t}\left(p^{t-1}, p^{t}, p^{t+1}\right)}_{\begin{array}{c}
\text { Pollution } \\
\text { externality }
\end{array}}-\underbrace{(1-\alpha) \tau^{t} \psi^{t}\left(p^{t-1}, p^{t}, p^{t+1}\right)}_{\begin{array}{c}
\text { Net cost of } \\
\text { taxation }
\end{array}}-\underbrace{\theta\left(\tau^{t}-\tau^{t-1}\right)^{2}}_{\begin{array}{c}
\text { Cost of policy } \\
\text { adjustment }
\end{array}}
\end{gathered}
$$

As already discussed, welfare maximization with respect to prices is likely to create time inconsistency issues since period- $t$ welfare would depend on the jump variable $p^{t+1}$. However, in the tax games analyzed below, the regulator now chooses taxes, while leaving pricing decisions to the durable goods monopolist.

\subsubsection{Timing}

Having established the implications of taxation for welfare and profits, we now define the timing of the interactions between the two parties. We consider a setting where the monopolist and the regulator make their decisions simultaneously in each period. The assumption of simultaneity describes a situation in which the monopolist is unaware of the regulator's current tax rate prior to setting the price. This describes the common situation in which firms make decisions before the details of current tax policies have been announced to the public. It is likely that there would be some scope for discussion of risk and option value in this model. We leave these issues for future research.

The timing assumption is crucially important for our results. The simultaneity of decisions causes the monopolist's current price choice to be 
independent of current taxes. This removes the jump state from the regulator's objective and remedies his time inconsistency problem. If the monopolist knew the current period's taxes, the regulator could influence the current period's price. The regulator's current payoff would then depend on his next period's choice and thus his time inconsistency problem will remain.

\subsubsection{The equilibrium of the regulation game}

In this section we formulate the above problem as a dynamic game and then solve for the subgame-perfect equilibrium tax and pricing strategies. We model regulation as a game between the various temporal incarnations of the regulator and the monopolist. When the regulator sets the current tax rate $\tau^{t}$, he takes in to account not only the consequences of his decision for the future behaviour of the monopolist, but also the effect on the behaviour of his own future selves. Similarly, when the durable goods monopolist chooses the current price $p^{t}$, he takes into account the implications for current profits, future regulation, as well as the behaviour of his future selves.

Again, we focus on the Markov perfect equilibrium of the taxation game. This will enable us to compare our results to the benchmarks studied in the previous chapter. The period- $t$ strategies of the regulator and the monopolist are restricted to be functions of the two payoff-relevant state variables:

1. the previous period's price $p^{t-1}$; and,

2. the previous period's tax level $\tau^{t-1}$. 
Let the strategies of the regulator and the monopolist be $\tau^{t}=f\left(p^{t-1}, \tau^{t-1}\right)$ and $p^{t}=g\left(p^{t-1}, \tau^{t-1}\right)$, respectively. We assume that these functions are continuously differentiable. This allows us to use dynamic programming to characterise them and rules out a potential multiplicity of equilibria.

Also, we need to specify how players form their expectations about future prices. Just as before, we assume that agents have perfect rational expectations: they correctly anticipate future prices both on and off the equilibrium path. Given our focus on Markov strategies, this assumption implies that $p_{e}^{t+1}=g\left(p^{t}, \tau^{t}\right)$.

To solve for the equilibrium strategies, we formulate the problems of the monopolist and the regulator recursively. The solution concept of Markov perfect equilibrium requires that these strategies solve a pair of Bellman equations. The regulator's Bellman equation states that the equilibrium tax rate must maximise the net present value of welfare:

$$
\begin{array}{r}
W\left(p^{t-1}, \tau^{t-1}\right) \\
=\max _{\tau^{t}}\left\{w\left(p^{t-1}, g\left(p^{t-1}, \tau^{t-1}\right), g\left(g\left(p^{t-1}, \tau^{t-1}\right), \tau^{t}, \tau^{t-1}\right), \tau^{t}\right)\right. \\
\left.+\delta W\left(g\left(p^{t-1}, \tau^{t-1}\right), \tau^{t}\right)\right\} .
\end{array}
$$

The monopolist's Bellman equation states the equilibrium pricing strategy must maximise the discounted stream of profits:

$$
\begin{array}{r}
\Pi\left(p^{t-1}, \tau^{t-1}\right)=\max _{p^{t}}\left\{\pi\left(p^{t-1}, p^{t}, g\left(p^{t}, f\left(p^{t-1}, \tau^{t-1}\right)\right), f\left(p^{t-1}, \tau^{t-1}\right)\right)\right. \\
\left.+\delta \Pi\left(p^{t}, f\left(p^{t-1}, \tau^{t-1}\right)\right)\right\} .
\end{array}
$$


Moreover, time invariance of Markov-perfect strategies requires that

$$
\begin{array}{r}
f\left(p^{t-1}, \tau^{t-1}\right) \\
=\arg \max _{\tau^{t}}\left\{w\left(p^{t-1}, g\left(p^{t-1}, \tau^{t-1}\right), g\left(g\left(p^{t-1}, \tau^{t-1}\right), \tau^{t}, \tau^{t-1}\right), \tau^{t}\right)\right. \\
\left.+\delta W\left(g\left(p^{t-1}, \tau^{t-1}\right), \tau^{t}\right)\right\},
\end{array}
$$

and

$$
\begin{array}{r}
g\left(p^{t-1}, \tau^{t-1}\right)=\arg \max _{p^{t}}\left\{\pi\left(p^{t-1}, p^{t}, g\left(p^{t}, f\left(p^{t-1}, \tau^{t-1}\right)\right), f\left(p^{t-1}, \tau^{t-1}\right)\right)\right. \\
\left.+\delta \Pi\left(p^{t}, f\left(p^{t-1}, \tau^{t-1}\right)\right)\right\} .
\end{array}
$$

The recursive formulation yields strategies that prescribe optimal actions for any values of the state variables. Thus, optimality is ensured for any history of play. Consequently, the Markov-perfect equilibrium is also subgame perfect, and therefore time consistent.

\subsubsection{Resolving the regulator's time inconsistency}

An inspection of the regulator's Bellman equation (4.5) reveals that its right hand side no longer depends on the regulator's future decision, $\tau^{t+1}$, but only on his current strategy, $\tau^{t}$, and the current state, $\left(p^{t-1}, \tau^{t-1}\right)$. Thus, delegation resolves the regulator's time consistency problem by effectively removing the jump variable from instantaneous welfare. The economic interpretation is that the regulator's period- $(t+1)$ decision no longer imposes an externality on period- $t$ welfare.

In our setting, taxation serves as an intrapersonal commitment device: the current regulator is unable to interfere in the choice of the current price. 
Note that the social planner is free to affect future prices. However, the period $t$ and $t+1$ regulators do not disagree about the choice of $p^{t+2}$. Thus, if the cost of delegation is low, they will provide the monopolist with incentives to choose the first-best (i.e. precommitment) price path. ${ }^{2}$

The above observation is crucially dependent upon the assumption of simultaneous choice of prices and taxes. If the monopolist knew the tax rate before he set his price level, the current regulator would be able to influence the monopolist's current price choice. This would create a temptation for the regulator to deviate from the plan preferred by his predecessor. Analytically, there would still be a jump variable in instantaneous welfare.

\subsubsection{Equilibrium strategies}

Bellman equations (4.5)-(4.8) yield a pair of Euler equations which characterise the equilibrium strategies of the monopolist and the regulator. They are provided in the following proposition.

Proposition 1. Suppose that Assumptions 1, 2 and 3 are satisfied. The Markov perfect equilibrium strategies solving the taxation game from period 2 onward satisfy the necessary conditions defined by the following generalised Euler-Lagrange equations:

\section{Regulator's condition}

$$
w_{1}^{t}-g_{1}^{t}\left[\frac{\delta w_{4}^{t}+w_{5}^{t-1}}{\delta g_{2}^{t}}\right]+\frac{\delta w_{2}^{t-1}+w_{3}^{t}}{\delta^{2}}+\frac{\delta w_{4}^{t-1}+w_{5}^{t-2}}{\delta^{2} g_{2}^{t-1}}=0 \quad \forall \quad t \geq 0
$$

\footnotetext{
${ }^{2}$ If $\theta=0$ then $\tau^{t-1}$ is not an element of the payoff function and the resulting equilibrium, while time consistent, will no longer be Markov-perfect.
} 
Monopolist's condition

$$
\begin{aligned}
\pi_{3}^{t} g_{2}^{t+1} & +\pi_{4}^{t}+\frac{\pi_{2}^{t-1}+\pi_{3}^{t-1} g_{1}^{t}+\delta \pi_{1}^{t}}{\delta f_{1}^{t}} \\
& =\delta f_{2}^{t+1}\left[\pi_{3}^{t+1} g_{2}^{t+2}+\frac{\pi_{2}^{t}+\pi_{3}^{t} g_{1}^{t+1}+\delta \pi_{1}^{t+1}}{\delta f_{1}^{t+1}}\right] \quad \forall \quad t \geq 0 .
\end{aligned}
$$

Proof. See Appendix B.2.

\subsection{Comparison with benchmarks}

If we substitute the derivatives of (4.4), we can rewrite the regulator's Euler equation as

$$
\begin{gathered}
\pi_{3}^{t-1}+C S_{3}^{t-1}-\psi_{3}^{t-1}+(\alpha-1) \tau^{t-1} \psi_{3}^{t-1} \\
+\frac{1}{g_{2}^{t}}\left[(\alpha-1) \psi^{t-1}+2 \theta\left(\delta\left(\tau^{t}-\tau^{t-1}\right)-\left(\tau^{t-1}-\tau^{t-2}\right)\right)\right] \\
+\delta\left(\pi_{2}^{t}-\psi_{2}^{t}+C S_{2}^{t}+(\alpha-1) \tau^{t} \psi_{2}^{t}\right)+\delta^{2}\left(\pi_{1}^{t+1}-\psi_{1}^{t+1}+C S_{1}^{t+1}+(\alpha-1) \tau^{t+1} \psi_{1}^{t+1}\right) \\
-\frac{\delta g_{1}^{t+1}}{g_{2}^{t+1}}\left[(\alpha-1) \psi^{t}-2 \theta\left(\tau^{t}-\tau^{t-1}\right)+2 \delta \theta\left(\tau^{t+1}-\tau^{t}\right)\right]=0 .
\end{gathered}
$$

When $\theta=0$ and $\alpha=1$, this equation replicates the precommitment Euler equation, (3.24). The implication is that if policy adjustment costs are zero and the government's valuation of the tax revenue is equal to the firm's valuation of the cost of taxation, then the regulator will choose the tax rate in such a way as to induce the monopolist to follow the first-best price path.

Our taxation mechanism provides the regulator with commitment opportunities for one period at a time. It enables him to overcome his time inconsistency. As long as his incentives are not distorted by other considerations, he can achieve the first best outcome. In chapter 5 we explore 
the extent to which the price is distorted by revenue valuation and costs of changing policy. 


\section{Chapter 5}

\section{Computation}

The previous chapter analytically demonstrated that the outcome of the regulation game replicates the first-best price path, which is likely to be different from the second best and laissez-faire outcomes. However, it was not possible to explore comparative statics, since characterization was provided with difference-differential Euler equations. In this chapter we develop a numerical example of the regulation game to investigate the impact of parameter changes on the outcome of the game.

First, our model is given specific functional form and solved for strategies and a steady state. We then vary the parameter values in order to assess the effect upon both the transition path and the resulting steady state.

In the interests of brevity, a numerical solution for the first-best and second-best paths is not provided. The previous chapter has already characterised those analytically, so a numerical simulation can add little insight. 


\subsection{Defining the model}

To solve our model numerically, we need to specify functional forms for agents' payoffs.

\subsubsection{The demand function}

For simplicity, consumers' tastes are assumed to be uniformly distributed across the support: $\phi(v)=1$. This implies that $\Phi(v)=v$ and demand is therefore

$$
x^{t}=p^{t-1}-(\beta+1) p^{t}+\beta p^{t+1} .
$$

\subsubsection{The welfare function}

To construct welfare, the cost function and the pollution function must be defined. The monopolist's cost function is assumed to be quadratic:

$$
C\left(x^{t}\right)=\frac{\rho}{2}\left(x^{t}\right)^{2}
$$

This specification guarantees that assumption 2 is satisfied. Furthermore, we assume that the pollution function is linear:

$$
\psi\left(x^{t}\right)=\kappa x^{t}
$$

Substituting (5.1) into the consumer surplus defined in equation (3.12) yields

$$
C S^{t}=\frac{1}{2}\left(1-\left(\beta p^{t+1}\right)^{2}+\left(p^{t}\right)^{2}\right)+\beta\left(p^{t}\right)^{2}-p^{t} p^{t-1} .
$$

Combining equations (5.1), (5.2) and (3.10) delivers the monopolist's 
instantaneous profit

$$
\begin{aligned}
\pi^{t}=-\frac{1}{2}\left((\beta+1) p^{t}-\beta p^{t+1}-\right. & \left.p^{t-1}\right) \\
& {\left[(2+(\beta+1) \rho) p^{t}-\rho\left(p^{t-1}+\beta p^{t+1}\right)\right] . }
\end{aligned}
$$

Finally, combining the above equations into the form of (3.14) gives us welfare. For brevity, that function is not reproduced here.

The initial parameter values used in the system of equations are shown in Table 5.1. They give us a base case scenario, which is a starting point of our analysis.

\begin{tabular}{|l|c|c|}
\hline Description & Symbol & Value \\
\hline Government revenue valuation & $\alpha$ & 1 \\
Cost of policy adjustment & $\theta$ & 0.5 \\
Production cost coefficient & $\rho$ & 1 \\
Pollution cost coefficient & $\kappa$ & 3 \\
Consumer discount factor & $\beta$ & 0.5 \\
Bellman discount rate & $\delta$ & 0.8 \\
\hline
\end{tabular}

Table 5.1: Base case parameter values

\subsection{Solving the model}

Having specified the problem, we now solve it numerically. Since this problem is linear in its state dynamics and quadratic in the players' payoffs, it will generate a Markov-perfect equilibrium in linear strategies. Hence, we conjecture that the strategy functions which solve the players' Euler 
equations have forms

$$
\begin{aligned}
& f\left(p^{t-1}, \tau^{t-1}\right)=\alpha_{r}+\gamma_{r 1} p^{t-1}+\gamma_{r 2} \tau^{t-1}, \\
& g\left(p^{t-1}, \tau^{t-1}\right)=\alpha_{m}+\gamma_{m 1} p^{t-1}+\gamma_{m 2} \tau^{t-1} .
\end{aligned}
$$

The subscripts $m$ and $r$ denote the coefficients on the the monopolist's and regulator's strategy parameters.

Substituting the derivatives of welfare and the strategy conjectures into the generalised Euler equations gives us a system of equations that can be solved numerically. We determine the strategy parameters in equations (5.6) using the method of undetermined coefficients For brevity the solution procedure is not presented here. The numerical results of the simulations can be found in Appendix C.

\subsection{Base case}

This section presents the results of our simulations. We first explain the intuition behind the numerical example. Then we examine the effect of varying some of the key parameters listed in Table 5.1. The equivalence of the regulatory game and the first best is not explicitly discussed here because this result has been demonstrated generally in the previous chapter.

In order to compare outcomes across various parameter values, two approaches are utilised. First, a comparison of convergence paths is made for variation in time preference parameters, $\delta$ and $\beta$. Secondly, a comparison of steady states is made across all parameter values.

However, before turning to comparative statics, we outline the results from the base line scenario and discuss some of the less intuitive elements 
of the simulation.

\section{Prices and demand}

Let us first examine the trajectories of prices and demand. They are shown in Figures 5.1a and 5.1c overleaf.

The price is falling over time as the market participants with the greatest valuation of the good purchase and exit the market. Therefore, condition (3.1) is satisfied. The price gradually converges towards a steady state of $\bar{p} \approx 1.2$ (see Appendix $C$ for a precise value). It should be noted that the steady state is an asymptote of the price trajectory and is not reached in finite time.

Demand declines over time as the price differences across periods diminish. If the price were to reach the steady state level, demand would drop to zero. But since the steady state is approached only asymptotically, demand is positive in all periods. As demand declines, so does the level of pollution generated by production (Figure 5.1e).

Notably, firm profits are negative in this example. This raises the question of why would this firm want to stay in business. Remember that the profits reported in Figure 5.1d are after-tax. Pre-tax profits happen to be positive in all periods. As the monopolist cares about net profits, the regulator could return the tax revenues to the monopolist as a lumpsum transfer to keep him in business. Indeed, the point of taxation in this model is to induce optimal behaviour, not to redistribute wealth. Thus, there is nothing inherently objectionable about returning the revenues to the monopolist. So long as the government's transfers to the monopolist are not conditional on the current state variables, the efficiency of the mo- 


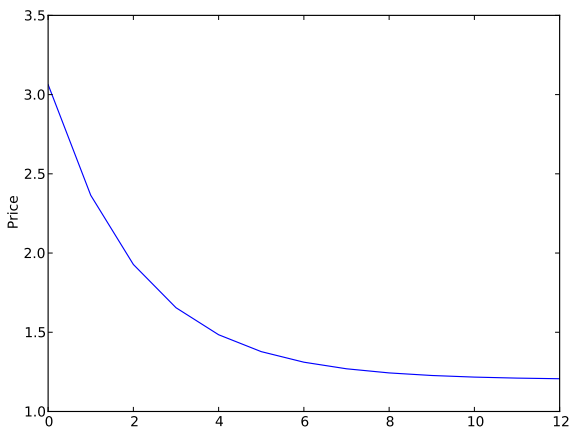

(a) Monopolist's price

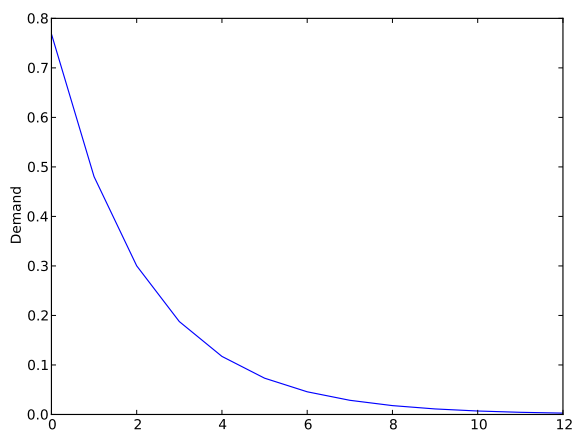

(c) Demand

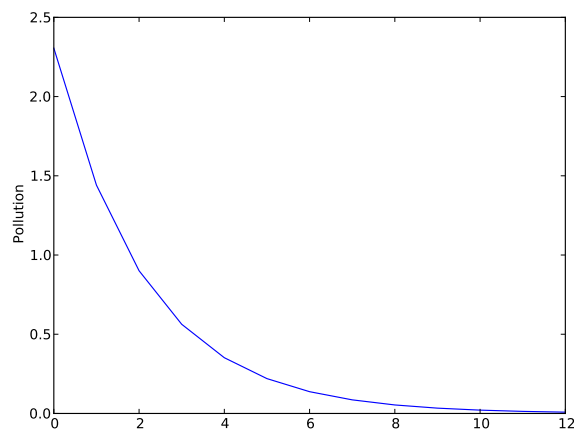

(e) Pollution

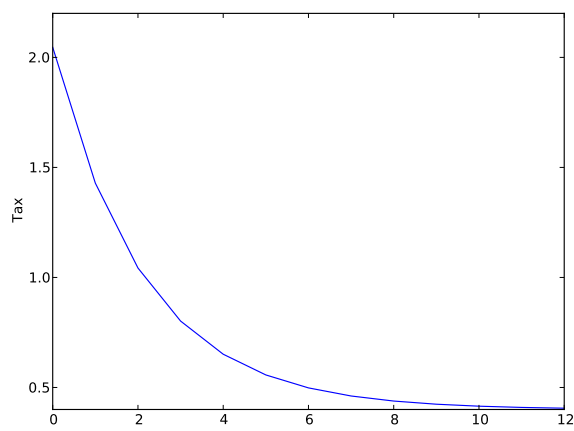

(b) Regulator's tax

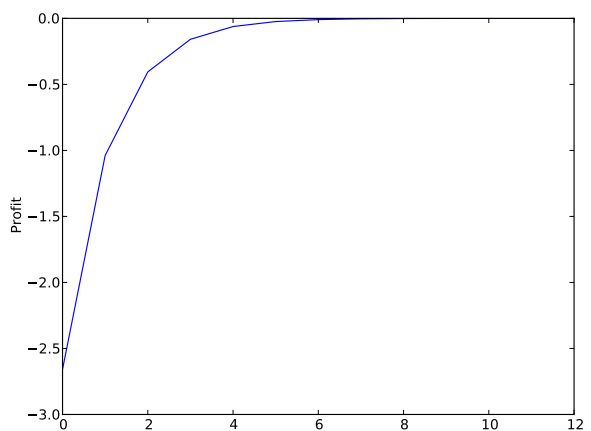

(d) Monopolist's profit

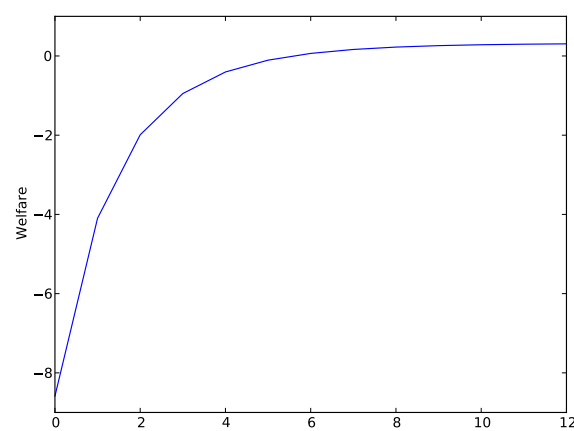

(f) Welfare

Figure 5.1: Convergence in the base case over 12 periods 
nopolist's decisions will not be affected.

Given our initial conditions, the equilibrium tax rate is also declining over time as pollution levels are reduced. In the steady state the level of taxation is about a third of the sale price $(\bar{\tau} \approx 0.4)$. The declining pollution externality reduces the need for taxation to alleviate the problem. In addition, the monopolist's time inconsistency causes them to charge a lower price in the current period in order to offset their incentive for a price reduction in the following period. As prices in consecutive periods converge over time, that incentive is reduced. Consequently, the level of taxation required to correct for the monopolist's inconsistency also declines.

The final variable charted in Figure 5.1 is instantaneous welfare. It is initially negative but converges to a positive value as the pollution level drops. The positive value of the welfare is driven by consumer surplus. ${ }^{1}$

So far, the convergence paths of each variable in the base case accord with what might be expected. Having canvassed them, we now turn to variations of the parameters in Table 5.1 and the effect that such variations have on the convergence paths and steady state levels of $\bar{p}$ and $\bar{\tau}$.

\subsection{Varying parameters}

Variation of the parameters is conducted in two parts. First, variations that affect the convergence paths are considered. The simulation results

\footnotetext{
${ }^{1}$ Readers may be concerned about the negative values of profit and welfare in the early periods. Note first that steady-state welfare and profits are non-negative. Then the values for each off the equilibrium path are entirely determined by the initial conditions. An arbitrarily different choice of initial conditions could generate everywhere-positive profits and/or welfare.
} 
demonstrate that the parameters with the greatest impact upon convergence paths are the time preference parameters, $\delta$ and $\beta$. The remaining parameters have a negligible effect upon convergence rates: it would not be visible at the scale plotted above in Figure 5.1. Consequently, convergence plots are given only for those two variables.

The implications of the remaining variables for the equilibrium outcome are analysed solely through their effect on the steady state levels $\bar{p}$ and $\bar{\tau}$.

\subsubsection{Convergence across parameter values}

In this subsection, the effect of varying the time preference parameters on convergence rates is investigated.

\section{Varying $\beta$}

The first parameter that we vary is $\beta$, the consumer discount rate. It embodies both the rate of consumer time preference and the depreciation rate of the durable good. Consequently, it is rather lower than one might expect for an ordinary time preference rate. In the base case, we set it to $\beta=0.5$. For the variation we consider a range of values between 0.49 and 0.52 . Beyond that range the steady state of the system is not in the neighbourhood of the base case.

The results are shown in Figure 5.2 where $\beta=0.49$. The lower end of the range is denoted by the pale blue line and $\beta=0.52$, at the upper end, is in red. The first thing to notice is that the trajectory of demand is steeper when $\beta$ is lower. A lower value of $\beta$ decreases the value of postponing 


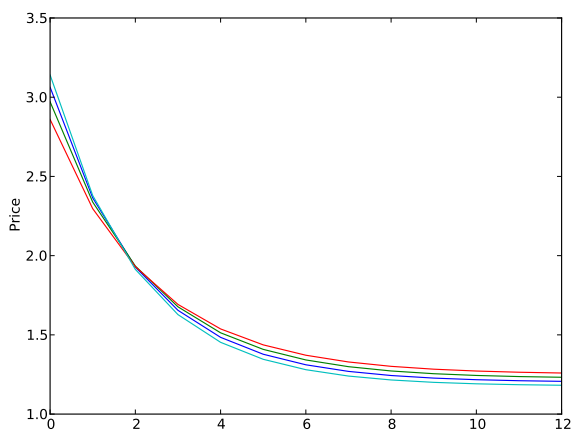

(a) Monopolist's price

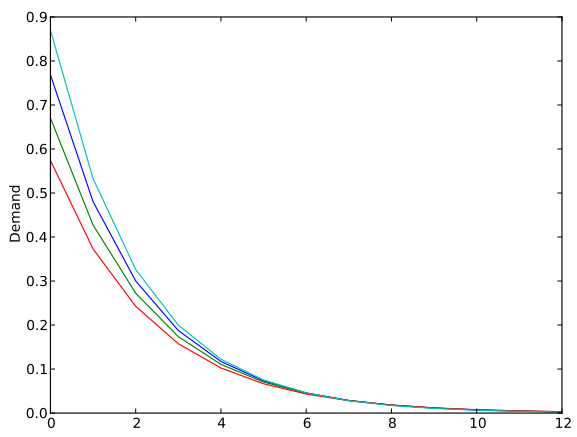

(c) Demand

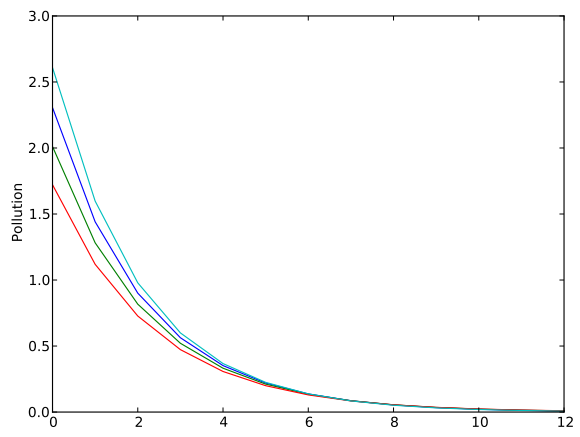

(e) Pollution

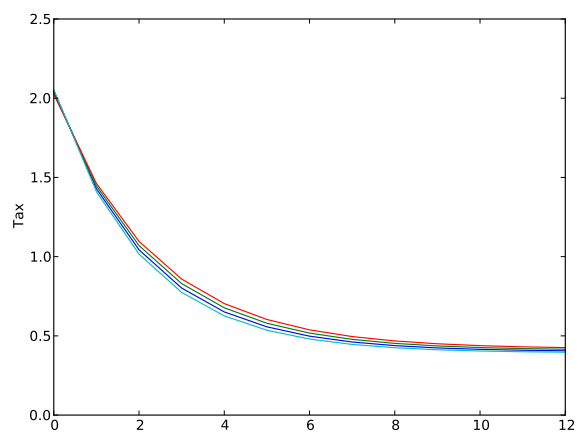

(b) Regulator's tax

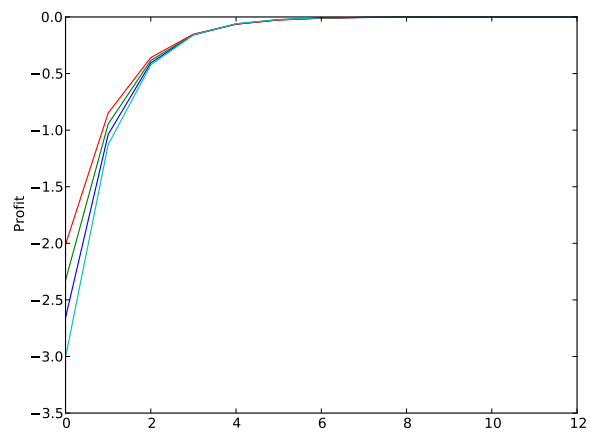

(d) Monopolist's profit

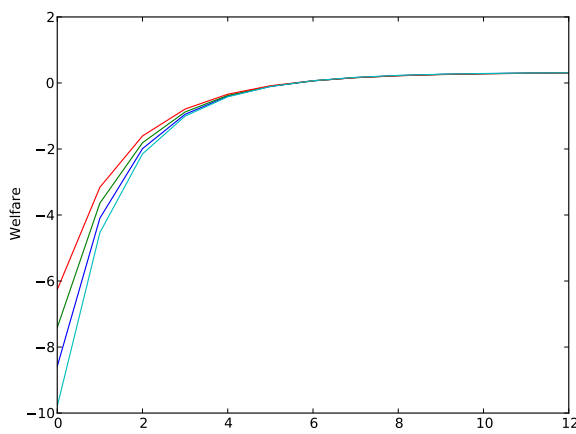

(f) Welfare

Figure 5.2: Convergence for $\beta \in\{0.49,0.5,0.51,0.52\}$ 
consumption, as the perceived value of the durable good in the next period is lower. Consequently, socially optimal consumption is shifted to earlier periods and demand is initially higher but falls more quickly since there is a constant mass of consumers. The increase in demand in early periods also pushes up pollution levels and results in higher total pollution flows, which also cost the monopolist profits due to the higher taxation. Interestingly, despite the higher pollution levels the regulator chooses not to change the tax rate significantly across the range of $\beta$ 's tested.

\section{Varying $\delta$}

The final part of our examination of convergence is an investigation of variations of the discount factor of the government and the monopolist, $\delta$. It describes how future payoffs are valued relative to the current period's payoff in the taxation game. The results are shown in Figure 5.3 and are very similar to the results for variation in $\beta$, as one might expect for another time preference parameter.

The only notable differences are in the magnitude of the effect and the impact upon the tax rate. The magnitude of the effect is slightly greater since $\beta$ influences all future values, rather then solely consumers' valuations of the durable good. However, it is the path of the tax rate that is more interesting.

In Figure $5.2 \mathrm{~b}$ the tax rate varied little between different values of $\beta$ whereas, in Figure 5.3b, the tax rate shows similar variation to the price path. 


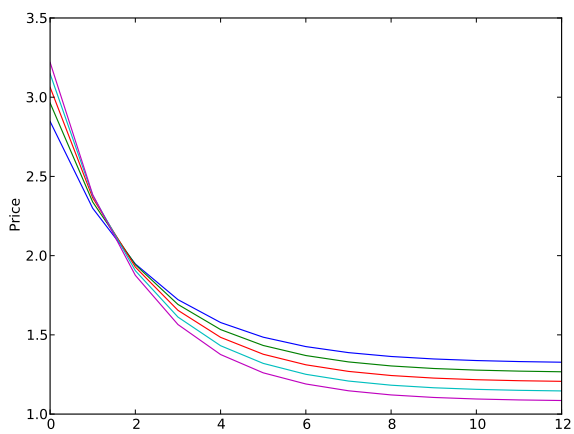

(a) Monopolist's price

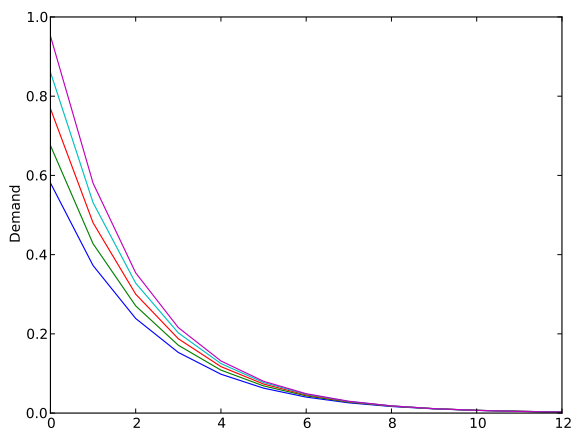

(c) Demand

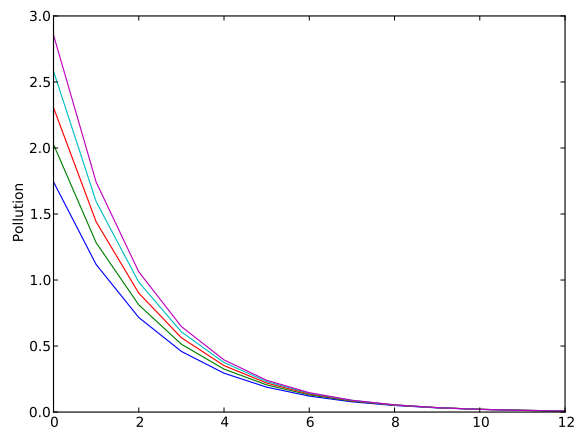

(e) Pollution

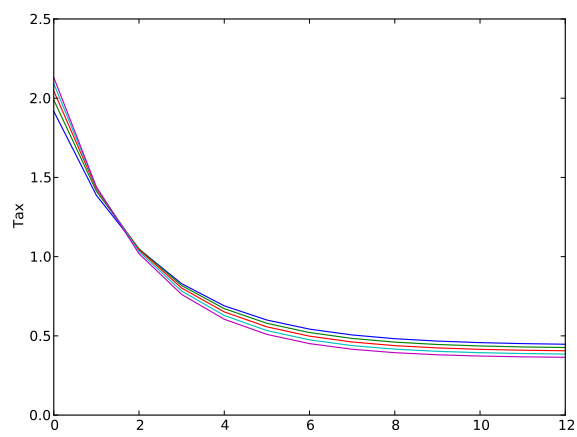

(b) Regulator's tax

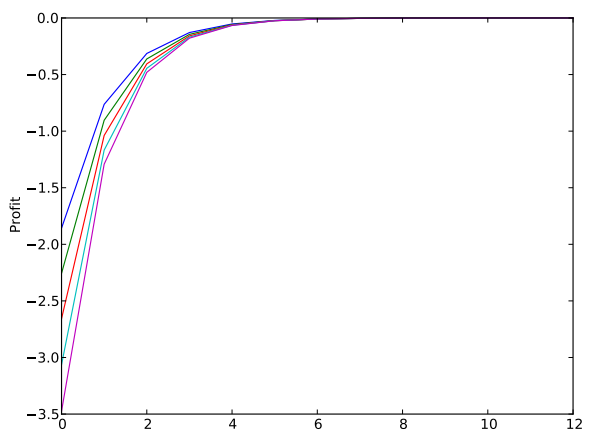

(d) Monopolist's profit

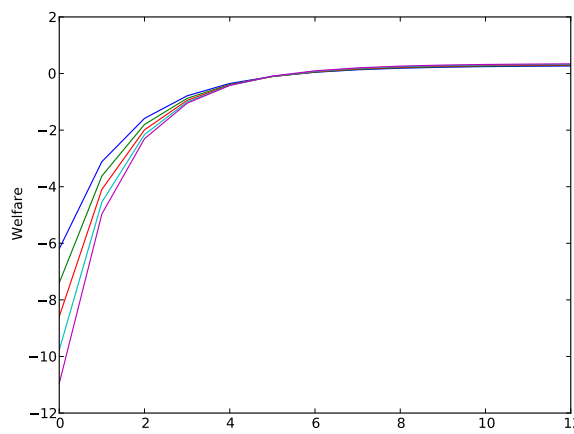

(f) Welfare

Figure 5.3: Convergence for $\delta \in\{0.78,0.79,0.8,0.81,0.82\}$ 


\subsubsection{Steady states across parameter values}

Having examined the impact on convergence of time preference rates we now turn to the steady state comparison. In this subsection we focus on the difference in steady states as the parameters vary. Figure 5.4 shows a scatter plot of $\bar{p}$ and $\bar{\tau}$ for pairs of parameter values. The pairs are chosen by the magnitude of their effect so the scale of the plot shrinks from Figure 5.4a through to Figure 5.4c.

A indicated in the previous section, the time preference rates have the greatest impact on the result and in a similar fashion; $\delta$ with greater magnitude than $\beta$. That is clearly shown by Figure 5.4a, which indicates that the effect of each on the steady state is identical in direction and varies only in magnitude. As agents reduce their valuation of future payoffs the monopolist is forced to lift their production and reduce their price in order to maintain demand for their product. That, in turn generates pollution and causes a commensurate lift in the tax rate to compensate.

In Figure $5.4 \mathrm{~b}$ the government's valuation of tax revenues, $\alpha$, and the pollution function's coefficient, $\kappa$, are varied. The effect of a drop in $\alpha$ is to increase the tax rate levied by the regulator while changing the rate of pollution has no effect upon the tax rate but does affect the price charged by the monopolist.

Finally, Figure 5.4c shows the negligible impact that the cost of policy changes, $\theta$, and the production cost coefficient, $\rho$, have on the steady state. Increasing $\rho$ causes the monopolist to increase prices, as might be expected when their marginal costs rise; however, the scale of the impact is such that it is an insignificant effect relative to that of time preference and the 
coefficient on pollution. 


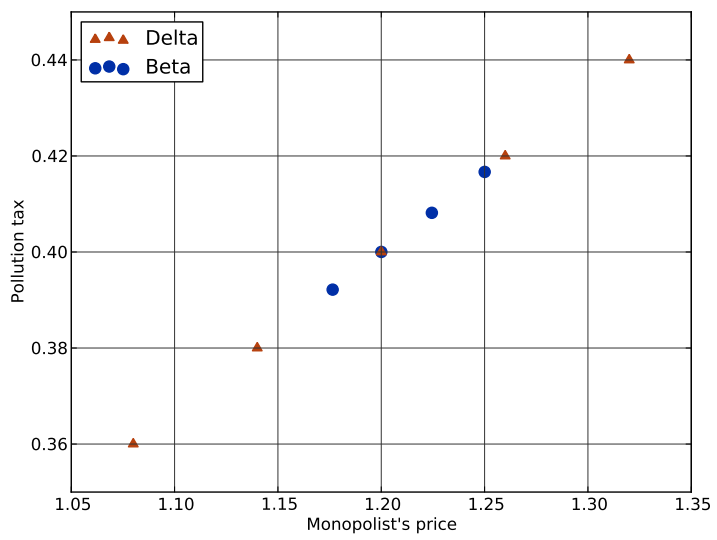

(a) $\beta \in\{0.49,0.5,0.51,0.52\}, \delta \in$ $\{0.78,0.79,0.8,0.81,0.82\}$

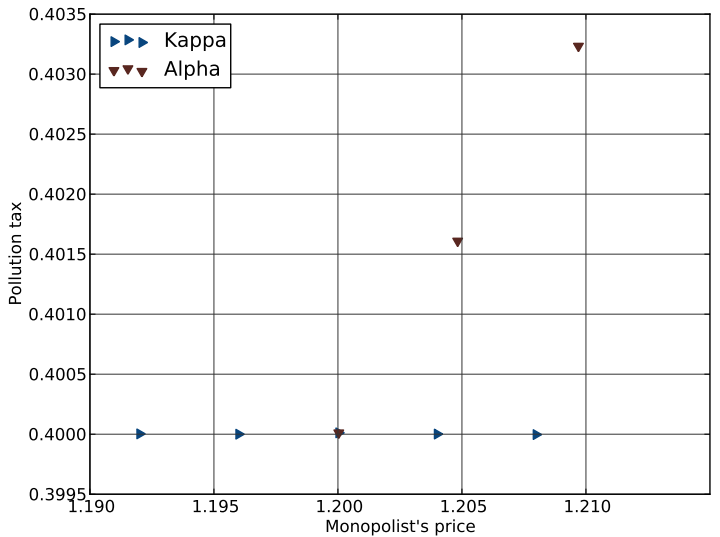

(b) $\kappa \in\{2.98,2.99,3,3.01,3.02\}, \alpha \in$ $\{0.98,0.99,1\}$

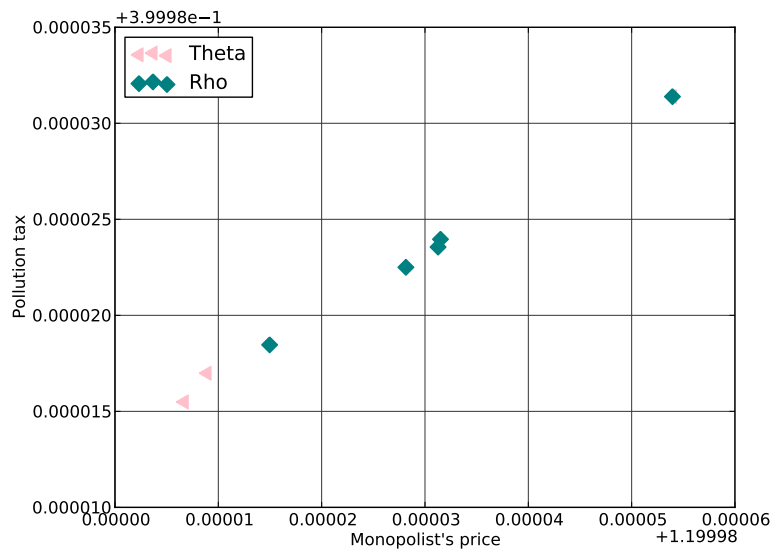

(c) $\theta \in\{0,0.01,0.02\}, \rho \in\{0.98,0.99,1,1.01,1.02\}$

Figure 5.4: Variation in steady states across parameter values 


\section{Chapter 6}

\section{Extension: a quasi-hyperbolic discounting model}

In Chapter 2.2 we mentioned that there are two main causes of dynamic inconsistency: jump states and hyperbolic discounting. The prior chapters of this thesis have dealt extensively with the issue of regulation in the presence of jump states. We developed a variant of a strategic delegation game to deal with inconsistency implied by a jump state. Inefficiencies due to hyperbolic discounting can be addressed in a similar way. In this chapter we demonstrate how the same mechanism can also be used by a regulator who suffers from inconsistency due to quasi-hyperbolic discounting.

We will argue that this type of inconsistency is different from the problem posed by jump states. However, the taxation mechanism described in chapter 4 can still attain the socially optimal outcome. 


\subsection{Quasi-hyperbolic discounting}

Hyperbolic discounting models originated from Ainslie (1992)'s empirical work. He showed that a hyperbolic curve is a far better match for the discount rate of most people than the standard exponential curve. When agents use hyperbolic discounting, their intertemporal trade-offs are not time invariant. Thus, such discount functions are not as mathematically easy to work with as exponential functions. Because of this difficulty Ainslie's book did not get the attention it deserved until the modifications by Laibson (1997) which made the analysis more tractable.

Rather than adopting a full hyperbolic function, Laibson introduced an exponential function with a modifier on the current period's discount rate. In Laibson's model, the discount factor for the next period is $\beta \delta$, where $0<$ $\beta<1$ and $0<\delta<1$. All subsequent periods are discounted exponentially by a factor $\delta$. This modification makes the model both simple to work with and a fair approximation of a hyperbolic function. Time preferences with this structure are known as quasi-hyperbolic preferences.

Quasi-hyperbolic discounting captures non-stationary time preferences, à la hyperbolic discounting, while preserving analytical tractability. Nonstationarity gives rise to time inconsistency, as the intertemporal trade-off between two successive periods will change with the agent's time reference. Consequently, precommitment has value similar to that in models with jump states.

In the following two chapters we develop a simple quasi-hyperbolic discounting model analogous to the monopolistic model of Chapter 3. Then we demonstrate the ability of the taxation game to correct both the 
regulator's time inconsistency as well as the pollution externality.

\subsection{The quasi-hyperbolic model}

As before, this model also involves a monopolist producing a good that creates a pollution externality. The regulator addresses inefficiencies caused by this externality through Pigouvian taxation. However, the regulator suffers from self-control problems induced by quasi-hyperbolic time preferences.

\subsection{Elements of the model}

The description of our model begins with a characterisation of the agents: a consumer, a monopolist and a regulator.

\subsubsection{The consumer}

Imagine a representative consumer who derives utility from two goods: a polluting good, $x$, and a numeraire, $m$. The consumer's instantaneous utility function is

$$
U(x, m)=u(x)+m .
$$

We assume that $u(x)$ satisfies the Inada conditions. This ensures that the inverse demand is well-defined for all positive values of $x$.

The consumer's budget constraint is

$$
p x+m=I .
$$


Therefore, inverse demand in this market is given by

$$
p=u^{\prime}(x)
$$

\subsubsection{The monopolist}

The market for good $x$ is served by a monopolist with a cost function $C(x)$ . His instantaneous profit function is

$$
\begin{aligned}
\pi(x) & =R(x)-C(x) \\
& =p x-C(x) .
\end{aligned}
$$

Equation (6.3) implies that profit can also be written as

$$
\pi(x)=u^{\prime}(x) x-C(x)
$$

The monopolist has standard exponential time preferences and is thus time consistent.

\subsubsection{The regulator}

Production generates a pollution externality that is not internalised by the monopolist. Unlike in the previous chapters, here pollution is modelled as a stock externality rather than a flow externality. The regulator has oversight of the monopolist and seeks to mitigate the damage wrought by the monopolist's emissions. The stock of pollution generated by the production of good $x$ at time $t$ is denoted by $k_{t} .{ }^{1}$ The environmental harm caused by this stock is $\varphi\left(k_{t}\right)$, where $\varphi^{\prime}\left(k_{t}\right)>0$.

\footnotetext{
${ }^{1}$ For tractability in this model we have switched from flow pollution to stock pollution.
} 
The stock of pollution evolves according to the following law-of-motion:

$$
k_{t}=\theta k^{t-1}+x^{t-1}
$$

The parameter $\theta \in[0,1)$ represents the rate of pollution carry-over. Instantaneous welfare is thus given by

$$
\begin{aligned}
w\left(x_{t}, k_{t}\right) & =\pi\left(x_{t}\right)+C S\left(x_{t}\right)-\varphi\left(k_{t}\right) \\
& =u^{\prime}\left(x_{t}\right) x_{t}-C\left(x_{t}\right)+\int_{0}^{x_{t}} u^{\prime}(x) d x-u^{\prime}\left(x_{t}\right) x_{t}-\varphi\left(k_{t}\right) \\
& =u\left(x_{t}\right)-C\left(x_{t}\right)-\varphi\left(k_{t}\right) .
\end{aligned}
$$

The regulator suffers from time inconsistency and is modelled as having quasi-hyperbolic preferences. In particular, his net present valuation of welfare from the period-t perspective is

$$
W_{t}=w\left(x_{t}, k_{t}\right)+\beta \sum_{i=1}^{\infty} \delta^{i} w\left(x_{t+i}, k_{t+i}\right) .
$$

Note the $\beta$ modifier in lifetime welfare. If $\beta=1$ then the preferences are 'exponential' and time consistent. If $\beta<1$, as is assumed here, then preferences are 'present biased' (i.e. non-stationary) and the regulator will experience dynamic inconsistency.

\subsection{Laissez-faire equilibrium}

First we consider the laissez-faire case. Suppose that the firm is not regulated by the government. The monopolist does not account for the damages arising from his pollution. As a result, the pollution stock does not appear in his payoff. In each period, the firm solves the following static 
problem:

$$
\max _{x} u^{\prime}(x) x-C(x) .
$$

The first order condition of this problem is

$$
u^{\prime \prime}\left(x^{\ell}\right) x^{\ell}+u^{\prime}\left(x^{\ell}\right)-C^{\prime}\left(x^{\ell}\right)=0,
$$

where $x^{\ell}$ denotes the laissez-faire level of output chosen by the monopolist. Intuitively, condition (6.13) delivers the output level at which marginal profit is equal to zero.

Since the monopolist discounts future payoffs exponentially, his lifetime profit is

$$
\sum_{t=0}^{\infty} \delta^{t} \pi_{t}=\frac{u^{\prime}\left(x^{\ell}\right) x^{\ell}-C\left(x^{\ell}\right)}{1-\delta}
$$

\subsection{Benchmarking regulation}

\subsubsection{First best regulation}

Before we analyse the taxation game, let us first benchmark the performance of a regulator who could choose output levels. Again, we first examine the problem of a hypothetical regulator who can both directly determine output and perfectly precommit to future policies.

Suppose that the regulator can directly choose the lifetime output plan $\left\{x_{t}\right\}_{t=0}^{\infty}$ at time 0 . The optimal plan would solve

$$
W_{0}=u\left(x_{0}\right)-C\left(x_{0}\right)-\varphi\left(k_{0}\right)+\beta \sum_{t=1}^{\infty} \delta^{t}\left[u\left(x_{t}\right)-C\left(x_{t}\right)-\varphi\left(k_{t}\right)\right]
$$

where the state variable evolves according to

$$
k_{t}=\theta k_{t-1}+x_{t-1},
$$


$\delta$ is the discount rate and $\beta$ is the quasi-hyperbolic modifier on the future discount factor.

The regulator's optimal choice will satisfy

$$
w_{1}^{0}+\beta \delta\left(w_{2}^{1}-\theta w_{1}^{1}\right)=0
$$

in period 0 , and

$$
w_{1}^{t}+\delta\left(w_{2}^{t}-\theta w_{1}^{t+1}\right)=0 \quad \forall t \geq 2 .
$$

for each subsequent period $t$. See Appendix D.1 for more detail.

Equations (6.16) and (6.17) together characterise the output path the regulator would choose, were he able to directly control output levels. From the perspective of the regulator at time 0 , this is the first best output path. After substituting $w\left(x_{t}, k_{t}\right)$ from (6.8), we obtain

$$
u^{\prime}\left(x_{t}\right)-C^{\prime}\left(x_{t}\right)-\delta \theta\left(u^{\prime}\left(x_{t+1}\right)-C^{\prime}\left(x_{t+1}\right)\right)-\delta \varphi^{\prime}\left(k_{t+1}\right)=0 \quad \forall t \geq 2 .
$$

This equation will be used for comparison with the laissez-faire condition, as they have similar forms.

\subsubsection{Comparison to laissez-faire outcome}

It is instructive to compare the first-best outcome to the laissez-faire equilibrium characterised in equation (6.13):

$$
u^{\prime}\left(x^{\ell}\right)-C^{\prime}\left(x^{\ell}\right)+u^{\prime \prime}\left(x^{\ell}\right) x^{\ell}=0 .
$$

Remember that this condition sets the monopolist's marginal profit to zero. Since profit is concave, marginal profit is a decreasing function. 
We focus on the steady state of the model. Suppose that $x_{t}=\bar{x}, \forall t$, and thus $k_{t}=\bar{k}, \forall t$. Now rearrange equation (6.18),

$$
u^{\prime}(\bar{x})-C^{\prime}(\bar{x})=\frac{\delta \varphi^{\prime}(\bar{k})}{1-\delta \theta}
$$

and add $u^{\prime \prime}(\bar{x}) \bar{x}$ to both sides:

$$
u^{\prime}(\bar{x})-C^{\prime}(\bar{x})+u^{\prime \prime}(\bar{x}) \bar{x}=\frac{\delta \varphi^{\prime}(\bar{k})}{1-\delta \theta}+u^{\prime \prime}(\bar{x}) \bar{x} .
$$

The left-hand side of the above equation represents the monopolist's marginal profit evaluated at the steady-state first best output level. Remember that marginal profit is a decreasing function. Thus, if $\frac{\delta \varphi^{\prime}(\bar{k})}{1-\delta \theta}+u^{\prime \prime}(\bar{x}) \bar{x}>0$ then $\bar{x}<x^{\ell}$ and vice versa.

Signing the component parts gives

$$
\begin{array}{r}
\delta \varphi^{\prime}(\bar{x})>0 \\
1-\beta \delta>0 \\
u^{\prime \prime}(\bar{x}) \bar{x}<0
\end{array}
$$

So if

$$
\frac{\delta \varphi^{\prime}(\bar{k})}{1-\delta \theta}>u^{\prime \prime}(\bar{x}) \bar{x}
$$

then $\bar{x}<x^{\ell}$. The left hand side of the inequality represents the lifetime marginal cost of the externality, while the right hand side is the deadweight loss due to monopoly power. The externality implies that the quantity produced may be too high from a welfare point of view, while the firm's market power suggests that production could be too low. Taxing the firm to reduce pollution is only worthwhile when the former effect outweighs the latter. Henceforth, we shall assume that equation (6.25) holds. 


\subsubsection{Second best regulation}

Sophisticated regulators would recognise that they have a time inconsistency problem. Therefore, they will try to avail themselves of a solution. If they unable to precommit to future policies, they will act strategically to influence the decisions of their future selves. Such behaviour would give rise to a time-consistent second best-output path. This path would occur if the regulator could directly choose output, but had no means of precommitting themselves to future decisions.

To solve for the time consistent equilibrium, we must formulate the problem recursively. Let the MPE strategy of the regulator be $x_{t}=f\left(k_{t}\right)$. Then his Bellman equation is

$$
U\left(k_{t}\right)=\max _{x_{t}}\left\{w\left(x_{t}, k_{t}\right)+\beta \delta V\left(\theta k_{t}+x_{t}\right)\right\}
$$

where $U(\cdot)$ is his current period's value function and $V(\cdot)$ is his continuation value function. The continuation value function captures the stream of future payoffs from period $t+1$ onward. It is different from the current period's value function because quasi-hyperbolic preferences are nonstationary. Since from next period onwards the regulator would discount welfare exponentially, the continuation value function must satisfy the recursive equation

$$
V\left(k_{t}\right)=w\left(f\left(k_{t}\right), k_{t}\right)+\delta V\left(\theta k_{t}+f\left(k_{t}\right)\right) .
$$

Dynamic programming renders a generalised Euler equation that characterises the regulator's output strategy:

$$
w_{1}^{t}+\beta \delta\left(w_{1}^{t+1} f_{1}^{t+1}+w_{2}^{t+1}\right)-\delta\left(\theta+f_{1}^{t+1}\right) w_{1}^{t+1}=0 .
$$


Note the difference between equation (6.28) and equation (6.17). This difference suggests that the time consistent path will not coincide with the first-best (i.e. precommitment) path.

\subsection{Regulation with delegation}

Intuitively it should be possible to solve a quasi-hyperbolic discounting problem through 'delegation' of the pricing decision.

Quasi-hyperbolic time preferences give rise to time inconsistent behaviour. However, the internal strategic conflict between two successive regulators, in periods $t$ and $t+1$, only concerns the choice of the period$t+1$ action. These two regulators do not disagree about future actions, as both will discount future payoffs exponentially. Thus, by eliminating the direct effect of today's decision on next period's payoff, it should be possible to render the regulator consistent.

In our delegation game, the regulator sets a tax rate for pollution simultaneously with the monopolist's choice of output. Both the tax and the output are feedback strategies. As in the previous chapters, we consider a linear tax on emissions.

\subsubsection{The welfare function}

Taxation affects the regulator's problem in two ways: first, he gains revenue from taxation and, secondly, there is a cost to changing the tax rate over time. Economists are often criticised that they do not account for the cost of taxes when they recommend them. That is why we explicitly 
include the costs of implementing and modifying tax schemes in the regulator's welfare function.

Suppose that the tax is levied on emissions and the revenue from the tax is given to consumers as a lump sum transfer. Since the marginal utility of income to consumers is 1 , the value of the revenue in the welfare function is equal to the cost of taxation borne by monopolist. Hence, the tax is a simple transfer of surplus and does not change total welfare.

Period- $t$ tax revenue is $\tau_{t} x_{t}$, where $\tau_{t}$ is the tax rate chosen by the government. Let the adjustment cost of changing policies be $\kappa \rho\left(\tau_{t}, \tau_{t-1}\right) .^{2}$ Then instantaneous welfare is given by

$$
w\left(x_{t}, k_{t}, \tau_{t}, \tau_{t-1}\right)=u\left(x_{t}\right)-C\left(x_{t}\right)-\varphi\left(k_{t}\right)-\kappa \rho\left(\tau_{t}, \tau_{t-1}\right) .
$$

Welfare is not directly affected by tax revenue, but changing the tax rate over time is costly for the regulator. This assumption introduces a 'stickiness' to the tax rate. Note that if $\kappa=0$, policy adjustment will be costless and the welfare function will not depend directly on the tax rate.

\subsubsection{The profit function}

Taxation implies that the monopolist's instantaneous profit will now have the following form:

$$
\pi_{t}=u^{\prime}\left(x_{t}\right) x_{t}-C\left(x_{t}\right)-\tau_{t} x_{t} .
$$

\footnotetext{
${ }^{2}$ A plausible, specific functional form might be $\left(\tau_{t}-\tau_{t-1}\right)^{2}$, as in Chapter 4.2.1.
} 


\subsubsection{The taxation game}

Next we set up a regulation game for this problem that mirrors the game discussed in Chapter 4.

\section{State variables and strategies}

The state variables in this game are the previous period's tax rate, $\tau_{t-1}$, and the stock of pollution, $k_{t}$. Note that the current period's tax rate is not a state variable, as it is set in the current period.

In each period, the monopolist chooses output simultaneously with the regulator's choice of the current tax rate. Let the MPE strategy of the monopolist be $x_{t}=h\left(\tau_{t-1}, k_{t}\right)$ and the MPE strategy of the regulator be $\tau_{t}=g\left(\tau_{t-1}, k_{t}\right)$.

\section{The regulator's problem}

The regulator Bellman equation is now given by

$$
\begin{aligned}
U\left(\tau_{t-1}, k_{t}\right)=\max _{\tau_{t}}\left\{w \left(h\left(\tau_{t-1}, k_{t}\right), k_{t},\right.\right. & \left.\tau_{t}, \tau_{t-1}\right) \\
& \left.+\beta \delta V\left(\tau_{t}, \theta k_{t}+h\left(\tau_{t-1}, k_{t}\right)\right)\right\} .
\end{aligned}
$$

The continuation value function $V$ solves the functional equation

$$
\begin{aligned}
V\left(\tau_{t-1}, k_{t}\right)=w\left(h\left(\tau_{t-1}, k_{t}\right), k_{t}, g\right. & \left.\left(\tau_{t-1}, k_{t}\right), \tau_{t-1}\right) \\
& +\delta V\left(g\left(\tau_{t-1}, k_{t}\right), \theta k_{t}+h\left(\tau_{t-1}, k_{t}\right)\right) .
\end{aligned}
$$




\section{The monopolist's problem}

Since the monopolist discounts exponentially there is no $\beta$ in his Bellman equation and it is standard:

$$
\Pi\left(\tau_{t-1}, k_{t}\right)=\max _{x_{t}}\left\{\pi\left(x_{t}, g\left(\tau_{t-1}, k_{t}\right)\right)+\delta \Pi\left(g\left(\tau_{t-1}, k_{t}\right), \theta k_{t}+x_{t}\right)\right\}
$$

\section{Equilibrium strategies}

From Bellman equations (6.31) - (6.33) we obtain the generalised EulerLagrange equations characterising the optimal strategies for each player.

Using dynamic programming techniques, we can derive the monopolist's Euler-Lagrange equation. It is given by

$$
\pi_{2}^{t} g_{1}^{t}+\frac{g_{1}^{t}}{g_{2}^{t}}\left(\theta \pi_{1}^{t}-\pi_{2}^{t} g_{2}^{t}-\frac{1}{\delta} \pi_{1}^{t-1}\right)-\frac{\theta \pi_{1}^{t-1}-\pi_{2}^{t-1} g_{2}^{t-1}-\frac{1}{\delta} \pi_{1}^{t-2}}{\delta g_{2}^{t-1}}=0 .
$$

See Appendix D.3.2 for the details.

The Euler-Lagrange equation characterising the regulator's strategy is

$$
\begin{gathered}
\frac{w_{3}^{t-1} g_{1}^{t-1}-\beta\left(w_{1}^{t-1} h_{1}^{t-1}+w_{3}^{t-1} g_{1}^{t-1}+w_{4}^{t-1}\right)}{\delta h_{1}^{t-1}}-\frac{w_{3}^{t-2}}{\delta^{2} h_{1}^{t-1}} \\
=\beta\left(w_{1}^{t} h_{2}^{t}+w_{2}^{t}+w_{3}^{t} g_{2}^{t}\right)-g_{2}^{t} w_{3}^{t} \\
+\frac{\left(\theta+h_{2}^{t}\right)}{h_{1}^{t}}\left[w_{3}^{t} g_{1}^{t}-\beta\left(w_{1}^{t} h_{1}^{t}+w_{3}^{t} g_{1}^{t}+w_{4}^{t}\right)-\frac{w_{3}^{t-1}}{\delta}\right] .
\end{gathered}
$$

The derivations are detailed in Appendix D.3.1.

To compare this game to the first-best outcome, let us consider the special case where $\kappa=0$, so policy change is costless. We substitute in the 
following partial derivatives of the welfare function:

$$
\begin{aligned}
& w_{1}^{t}=u^{\prime}\left(x_{t}\right)-c^{\prime}\left(x_{t}\right) \\
& w_{2}^{t}=-\varphi^{\prime}\left(x_{t}\right) \\
& w_{3}^{t}=0 \\
& w_{4}^{t}=0 .
\end{aligned}
$$

After this substitution, Euler equation (6.35) reduces to

$$
\frac{u^{\prime}\left(x_{t-1}\right)-c^{\prime}\left(x_{t-1}\right)}{\delta}-\varphi^{\prime}\left(x_{t}\right)-\theta\left(u^{\prime}\left(x_{t}\right)-c^{\prime}\left(x_{t}\right)\right)=0 .
$$

Multiplying by $\delta$ and shifting the equation forward one period yields

$$
u^{\prime}\left(x_{t}\right)-c^{\prime}\left(x_{t}\right)-\delta \varphi^{\prime}\left(x_{t+1}\right)-\delta \theta\left(u^{\prime}\left(x_{t+1}\right)-c^{\prime}\left(x_{t+1}\right)\right)=0 .
$$

Note that this replicates Euler equation (6.18) that characterizes the precommitment outcome. Therefore, the regulation game will deliver the first-best output path. 


\section{Chapter 7}

\section{Conclusions}

Time consistency is an important issue for regulators and can have serious implications for policy effectiveness. This thesis demonstrates that mechanism design can alleviate this problem. We construct a game that allows the regulator to attain the first best in a setting with externalities despite his time inconsistency.

We take a case study of a polluting monopolist and demonstrate that the regulator's time inconsistency can adversely affect welfare. The regulator's inability to precommit may prevent him from fully eliminating the inefficiency of the pollution externality. The main contribution is to show that careful policy design may provide the regulator with precommitment opportunities. The particular mechanism considered here is a modified version of a Pigouvian tax. Obviously, such an instrument is not appropriate for every situation. The general implication is that careful mechanism design could enable regulators to achieve first-best outcomes, even in the face of obstacles such as dynamic inconsistency.

Finally, it is worth pointing out that this thesis abstracts from many 
concerns facing regulators. We assume perfect information, discrete time, a single market, a single firm serving that market and limited heterogeneity among consumers. Further research in the field would do well to relax some of those assumptions and investigate the impact for regulators' ability to achieve first-best outcomes. 


\section{Appendix A}

\section{Concavity of the monopolist's profit function}

For concavity of the profit function we require $\frac{\partial^{2} \pi}{\partial\left(p^{t}\right)^{2}}<0$. Now, by differentiating equation (3.10) twice

$$
\frac{\partial^{2} \pi}{\partial\left(p^{t}\right)^{2}}=2 \frac{\partial x}{\partial p^{t}}-\frac{\partial x}{\partial p^{t}} C^{\prime \prime}(x)+\frac{\partial^{2} x}{\partial\left(p^{t}\right)^{2}}\left(p-C^{\prime}(x)\right)<0
$$

The term $2 \frac{\partial x}{\partial p^{t}}$ is negative because of the downward slope of the demand function and $-\frac{\partial x}{\partial p^{t}} C^{\prime \prime}(x)$ must also be negative since by Assumption 2 the cost function is convex. Now a monopoly will always set $P>M C$ so $p-C^{\prime}(x)$ must be positive. Hence, it is sufficient for concavity of the profit function that the demand function be weakly concave: $\frac{\partial^{2} x}{\partial\left(p^{t}\right)^{2}} \leq 0$.

Note that while this condition is sufficient it is not necessary since if the cost function were highly convex then a mildly convex demand function could still give a concave profit function.

Taking the second derivative of the demand function (equation (3.9)) 
gives

$$
\frac{\partial^{2} x}{\partial\left(p^{t}\right)^{2}}=\beta^{2} \Phi^{\prime \prime}\left(p^{t-1}-\beta p^{t}\right)-\Phi^{\prime \prime}\left(p^{t}-\beta p^{t+1}\right)<0 .
$$

Hence, the condition for concavity of the demand function is

$$
\beta^{2} \Phi^{\prime \prime}\left(p^{t-1}-\beta p^{t}\right)<\Phi^{\prime \prime}\left(p^{t}-\beta p^{t+1}\right) .
$$

Now, by equation (3.7), $p^{t-1}-\beta p^{t}>p^{t}-\beta p^{t+1}$ so (A.3) can only hold for all possible price trajectories if $\Phi^{\prime \prime \prime} \leq 0$. However, if $\Phi^{\prime \prime}<0$ then condition (A.3) still cannot be guaranteed to hold. It is sufficient to further assume that $\Phi^{\prime \prime} \geq 0$. Again, this is a sufficient rather than a necessary condition for concavity of the profit function. 


\section{Appendix B}

\section{Equilibria of the durable goods model}

\section{B.1 Time-consistency without precommitment}

To solve the game described in 3.3.2 by maximising the Bellman function (3.27) with respect to $p^{t}$ first differentiate it with respect to that variable to give the first-order condition

$$
\frac{\partial V^{t}}{\partial p^{t}}=w_{2}^{t}+w_{3}^{t} f_{1}^{t+1}+\delta V_{1}^{t+1}=0
$$

which rearranges to give

$$
V_{1}^{t+1}=-\frac{w_{2}^{t}+w_{3}^{t} f_{1}^{t+1}}{\delta}
$$

Now, to find the envelope condition that holds for the optimal strategy, differentiate $V^{t}$ with respect to the state variable $p^{t-1}$ :

$$
V_{1}^{t}=w_{1}^{t}+f_{1}^{t}\left(w_{2}^{t}+w_{3}^{t} f_{1}^{t+1}+\delta V_{1}^{t+1}\right)
$$


Since, at the optimal point, the first order condition from (B.1) holds, we know that $w_{2}^{t}+w_{3}^{t} f_{1}^{t+1}+\delta V_{1}^{t+1}=0$ and the envelope condition is thus

$$
V_{1}^{t}=w_{1}^{t}
$$

Now substituting the derivative of the Bellman value function from (B.4) into equation (B.2) gives equation (3.29).

\section{B.2 MPE of the taxation game}

This section demonstrates the solution to the game described in Section 4.2.

\section{The regulator's necessary condition}

The first order condition for the regulator is derived by differentiating the regulator's Bellman equation with respect to $\tau^{t}$ and setting it equal to zero.

$$
\frac{\partial W^{t}}{\partial \tau^{t}}=w_{3}^{t} g_{2}^{t+1}+\delta W_{2}^{t+1}=0
$$

Thus the Bellman value function for the regulator is characterised by

$$
W_{2}^{t+1}=-\frac{w_{3}^{t} g_{2}^{t+1}}{\delta}
$$

To solve for the generalised Euler-Lagrange equations which characterise the equilibrium strategies of the regulator and the monopolist it is necessary to find the envelope conditions in addition to the first-order condition. These are found by differentiating the Bellman value function with respect to the states:

$$
\begin{aligned}
& W_{1}^{t}=w_{1}^{t}+g_{1}^{t}\left(w_{2}^{t}+w_{3}^{t} g_{1}^{t+1}+\delta W_{1}^{t+1}\right)+f_{1}^{t}\left(w_{3}^{t} g_{2}^{t+1}+\delta W_{2}^{t+1}\right) \\
& W_{2}^{t}=g_{2}^{t}\left(w_{2}^{t}+w_{3}^{t} g_{1}^{t+1}+\delta W_{1}^{t+1}\right)+f_{2}^{t}\left(w_{3}^{t} g_{2}^{t+1}+\delta W_{2}^{t+1}\right)
\end{aligned}
$$


Since we know from the first order condition, (B.5), that $w_{3}^{t} g_{2}^{t+1}+\delta W_{2}^{t+1}=0$ in optimality it follows that the envelope conditions for the regulator's optimal strategy are

$$
\begin{aligned}
& W_{1}^{t}=w_{1}^{t}+g_{1}^{t}\left(w_{2}^{t}+w_{3}^{t} g_{1}^{t+1}+\delta W_{1}^{t+1}\right) \\
& W_{2}^{t}=g_{2}^{t}\left(w_{2}^{t}+w_{3}^{t} g_{1}^{t+1}+\delta W_{1}^{t+1}\right) .
\end{aligned}
$$

From these conditions and the first order conditions it is possible to solve for the Euler-Lagrange equations by eliminating the unknown Bellman value functions. First substituting (B.6) into (B.10) gives

$$
-\frac{w_{3}^{t-1} g_{2}^{t}}{\delta}=g_{2}^{t}\left(w_{2}^{t}+w_{3}^{t} g_{1}^{t+1}+\delta W_{1}^{t+1}\right)
$$

which simplifies to

$$
W_{1}^{t+1}=-\frac{w_{3}^{t-1}+\delta\left(w_{2}^{t}+w_{3}^{t} g_{1}^{t+1}\right)}{\delta^{2}}
$$

Now substituting (B.12) into (B.9) to eliminate the unknown Bellman value function derivative gives

$$
\begin{aligned}
& -\frac{w_{3}^{t-2}+\delta\left(w_{2}^{t-1}+w_{3}^{t-1} g_{1}^{t}\right)}{\delta^{2}}=w_{1}^{t} \\
& \quad+g_{1}^{t}\left(w_{2}^{t}+w_{3}^{t} g_{1}^{t+1}+\delta\left(-\frac{w_{3}^{t-1}+\delta\left(w_{2}^{t}+w_{3}^{t} g_{1}^{t+1}\right)}{\delta^{2}}\right)\right)
\end{aligned}
$$

which, shifted forward two period, simplifies to give equation (4.9).

\section{The monopolist's necessary condition}

The first order condition for the monopolist is derived by differentiating the monopolist's Bellman equation with respect to $p^{t}$ and setting it equal to zero.

$$
\frac{\partial \Pi^{t}}{\partial p^{t}}=\pi_{2}^{t}+\pi_{3}^{t} g_{1}^{t}+\delta \Pi_{1}^{t+1}=0
$$


The Bellman value function for the monopolist can then be characterised by the equation

$$
\Pi_{1}^{t+1}=-\frac{\pi_{2}^{t}+\pi_{3}^{t} g_{1}^{t}}{\delta}
$$

Now finding the envelope conditions for the monopolist as was done for the regulator:

$$
\begin{aligned}
& \Pi_{1}^{t}=\pi_{1}^{t}+g_{1}^{t}\left(\pi_{2}^{t}+\pi_{3}^{t} g_{1}^{t+1}+\delta \Pi_{1}^{t+1}\right)+f_{1}^{t}\left(\pi_{3}^{t} g_{2}^{t+1}+\pi_{4}^{t}+\delta \Pi_{2}^{t+1}\right) \\
& \Pi_{2}^{t}=g_{2}^{t}\left(\pi_{2}^{t}+\pi_{3}^{t} g_{1}^{t+1}+\delta \Pi_{1}^{t+1}\right)+f_{2}^{t}\left(\pi_{3}^{t} g_{2}^{t+1}+\pi_{4}^{t}+\delta \Pi_{2}^{t+1}\right)
\end{aligned}
$$

From the first order condition, (B.14), $\pi_{2}^{t}+\pi_{3}^{t} g_{1}^{t}+\delta \Pi_{1}^{t+1}=0$ and, hence, the envelope conditions for this problem are:

$$
\begin{aligned}
& \Pi_{1}^{t}=\pi_{1}^{t}+f_{1}^{t}\left(\pi_{3}^{t} g_{2}^{t+1}+\pi_{4}^{t}+\delta \Pi_{2}^{t+1}\right) \\
& \Pi_{2}^{t}=f_{2}^{t}\left(\pi_{3}^{t} g_{2}^{t+1}+\pi_{4}^{t}+\delta \Pi_{2}^{t+1}\right)
\end{aligned}
$$

Now to solve, first substitute (B.15) into (B.18) to give

$$
-\frac{\pi_{2}^{t-1}+\pi_{3}^{t-1} g_{1}^{t-1}}{\delta}=\pi_{1}^{t}+f_{1}^{t}\left(\pi_{3}^{t} g_{2}^{t+1}+\pi_{4}^{t}+\delta \Pi_{2}^{t+1}\right)
$$

which rearranges to

$$
\Pi_{2}^{t+1}=-\frac{\pi_{2}^{t-1}+\pi_{3}^{t-1} g_{1}^{t-1}+\delta \pi_{1}^{t}}{\delta^{2} f_{1}^{t}}-\frac{\pi_{3}^{t} g_{2}^{t+1}+\pi_{4}^{t}}{\delta} .
$$

Now substituting (B.21) into (B.19) eliminates the unknown Bellman value function derivative:

$$
\begin{aligned}
-\frac{\pi_{2}^{t-2}+\pi_{3}^{t-2} g_{1}^{t-2}+\delta \pi_{1}^{t-1}}{\delta^{2} f_{1}^{t-1}}-\frac{\pi_{3}^{t-1} g_{2}^{t}+\pi_{4}^{t-1}}{\delta} & \\
& =-f_{2}^{t} \frac{\pi_{2}^{t-1}+\pi_{3}^{t-1} g_{1}^{t-1}+\delta \pi_{1}^{t}}{\delta f_{1}^{t}}
\end{aligned}
$$

This, shifted forward two periods, simplifies to give equation (4.10). 


\section{Appendix C}

\section{Numerical results of}

\section{linear-quadratic example}

Included in this appendix are the raw results of the computations from Chapter 5. 


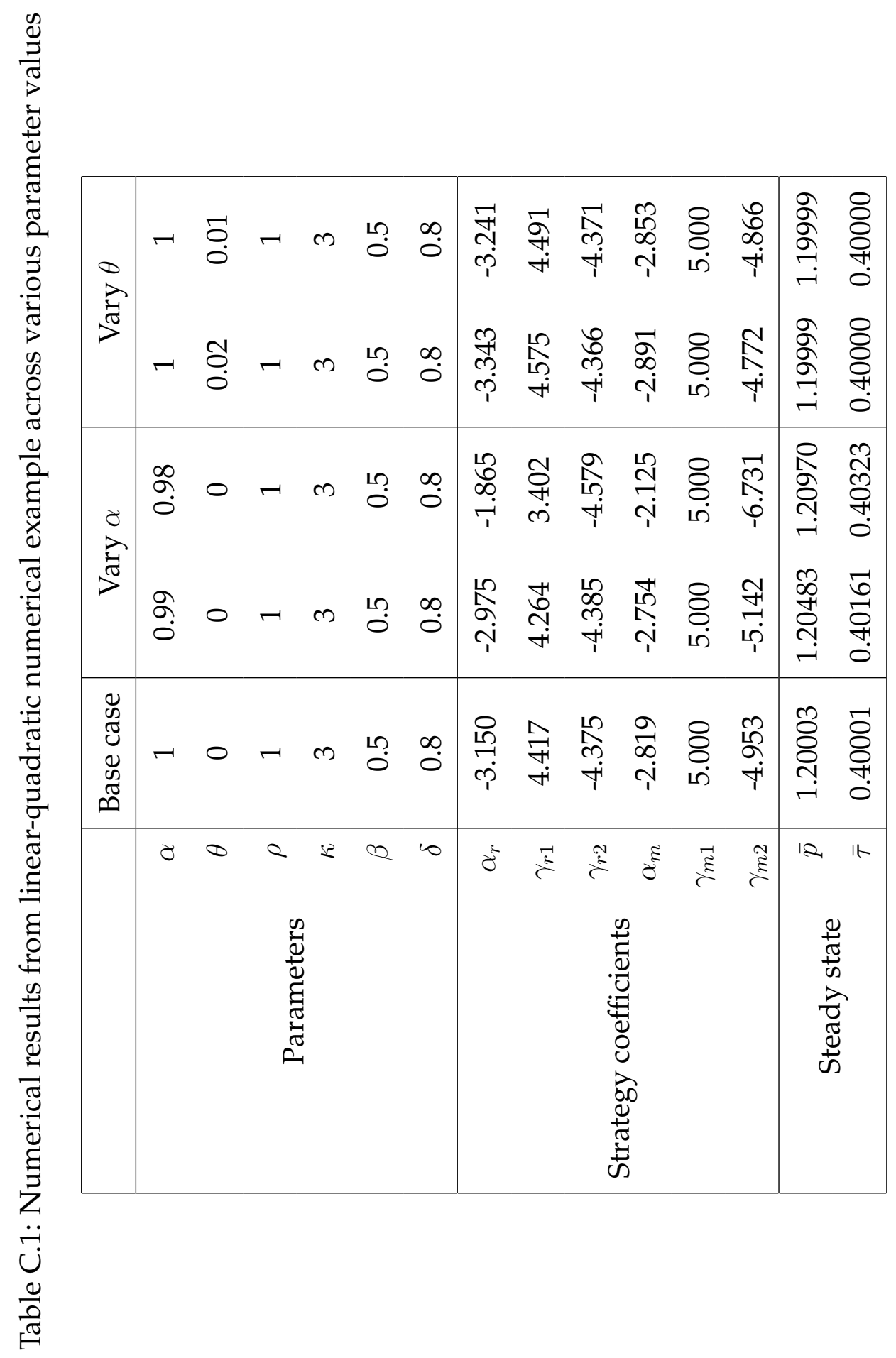




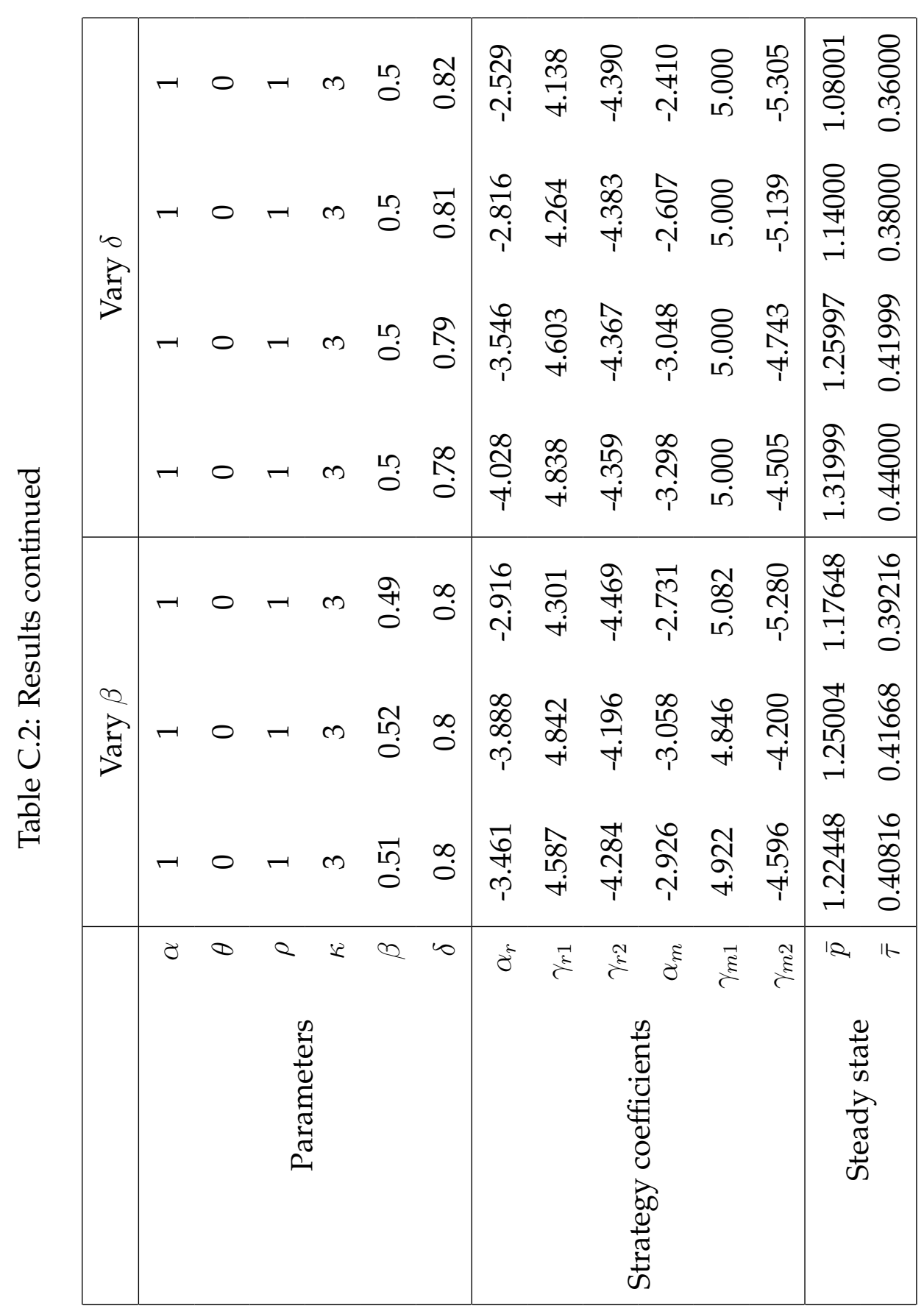




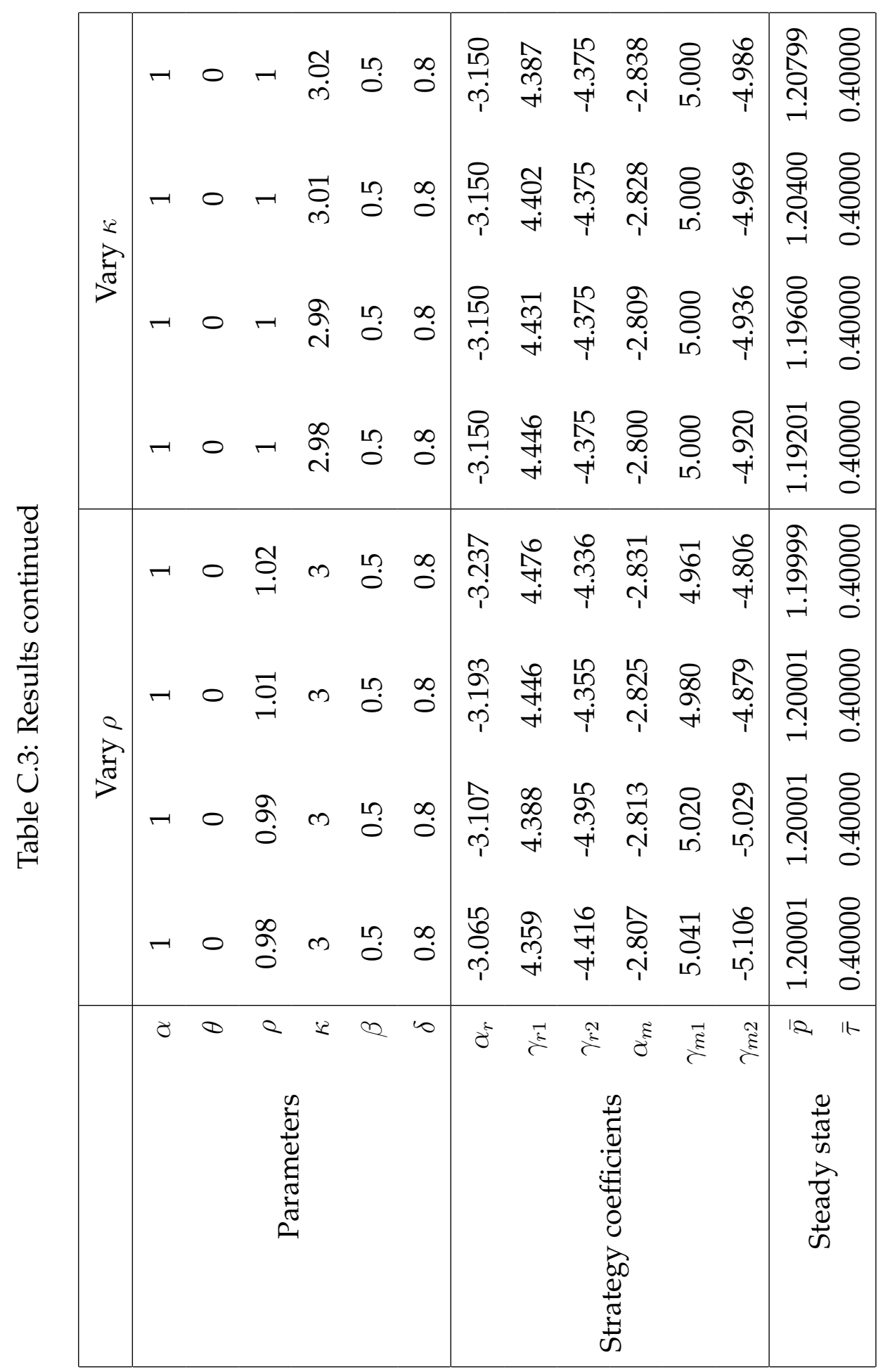




\section{Appendix D}

\section{Hyperbolic discounting equilibrium derivations}

\section{D.1 First best regulation}

Equations (6.15) and (6.8) can be combined to give lifetime welfare from the viewpoint of the period-0 regulator:

$$
W_{0}=w\left(x_{0}, k_{0}\right)+\beta \delta w\left(x_{1}, \theta k_{0}+x_{0}\right)+\beta \delta^{2} w\left(x_{2}, x_{1}+\theta x_{0}+\theta^{2} k_{0}\right)+\ldots
$$

Maximising this function requires taking first-order conditions with respect to $x_{t} \forall t \geq 0$. Derivatives are notated as usual with the time super- 
script taken from the time subscript of the state variable.

$$
\begin{aligned}
& \frac{\partial W_{0}}{\partial x_{0}}=w_{1}^{0}+\beta \delta w_{2}^{1}+\theta \beta \delta^{2} w_{2}^{2}+\ldots=0 \\
& \frac{\partial W_{0}}{\partial x_{1}}=\beta \delta w_{1}^{1}+\theta \beta \delta^{2} w_{2}^{2}+\theta \beta \delta^{3} w_{2}^{3}+\ldots=0 \\
& \frac{\partial W_{0}}{\partial x_{2}}=\beta \delta^{2} w_{1}^{2}+\theta \beta \delta^{3} w_{2}^{3}+\theta \beta \delta^{4} w_{2}^{4}+\ldots=0
\end{aligned}
$$

Compacting these conditions, (D.2) $-(\mathrm{D} .3) \times \theta$ gives

$$
w_{1}^{0}+\beta \delta\left(w_{2}^{1}-\theta w_{1}^{1}\right)=0,
$$

and $((\mathrm{D} .4)-(\mathrm{D} .6) \times \theta) / \beta \delta$ gives

$$
w_{1}^{t}+\delta\left(w_{2}^{t+1}-\theta w_{1}^{t+1}\right)=0 \quad \forall t \geq 2
$$

\section{D.2 Second best regulation}

The current period's first-order condition for welfare maximisation is

$$
\begin{aligned}
w_{1}^{t}+\beta \delta V_{1}^{t+1} & =0 \\
\therefore V_{1}^{t+1} & =-\frac{w_{1}^{t}}{\beta \delta} .
\end{aligned}
$$

Differentiating (6.27) gives

$$
V_{1}^{t}=w_{1}^{t} f_{1}^{t}+w_{2}^{t}+\delta V_{1}^{t+1}\left(\theta f_{1}^{t}\right)
$$

and substituting in equation (D.9) gives the Euler-Lagrange equation:

$$
w_{1}^{t}+\beta \delta\left(w_{1}^{t+1} f_{1}^{t+1}+w_{2}^{t+1}\right)-\delta\left(\theta+f_{1}^{t+1}\right) w_{1}^{t+1}=0 .
$$




\section{D.3 The regulation game}

\section{D.3.1 The regulator's problem}

To solve for the generalised Euler equation that characterises the welfare maximising price path we first take first order conditions:

$$
\begin{aligned}
w_{3}^{t}+\beta & \delta V_{1}^{t+1}=0 \\
\therefore V_{1}^{t+1} & =-\frac{w_{3}^{t}}{\beta \delta} .
\end{aligned}
$$

Taking the envelope conditions for this problem from equation (6.32) gives

$$
\begin{aligned}
& V_{1}^{t}=w_{1}^{t} h_{1}^{t}+w_{3}^{t} g_{1}^{t}+w_{4}^{t}+\delta\left[V_{1}^{t+1} g_{1}^{t}+V_{2}^{t+1} h_{1}^{t}\right] \\
& V_{2}^{t}=w_{1}^{t} h_{2}^{t}+w_{2}^{t}+w_{3}^{t} g_{2}^{t}+\delta\left[V_{1}^{t+1} g_{2}^{t}+V_{2}^{t+1}\left(\theta+h_{2}^{t}\right)\right]
\end{aligned}
$$

Solving for the Euler-Lagrange equation: (D.13) $\rightarrow$ (D.14) gives

$$
\begin{gathered}
w_{1}^{t} h_{1}^{t}+w_{3}^{t} g_{1}^{t}+w_{4}^{t}-\frac{w_{3}^{t} g_{1}^{t}}{\beta}+\delta V_{2}^{t+1} h_{1}^{t}+\frac{w_{3}^{t-1}}{\beta \delta}=0 \\
\therefore V_{2}^{t+1}=\frac{w_{3}^{t} g_{1}^{t}}{\beta \delta h_{1}^{t}}-\frac{w_{1}^{t} h_{1}^{t}+w_{3}^{t} g_{1}^{t}+w_{4}^{t}}{\delta h_{1}^{t}}-\frac{w_{3}^{t-1}}{\beta \delta^{2} h_{1}^{t}}
\end{gathered}
$$

Now (D.13), (D.16) $\rightarrow$ (D.15) gives the result

$$
\begin{gathered}
\frac{w_{3}^{t-1} g_{1}^{t-1}-\beta\left(w_{1}^{t-1} h_{1}^{t-1}+w_{3}^{t-1} g_{1}^{t-1}+w_{4}^{t-1}\right)}{\delta h_{1}^{t-1}}-\frac{w_{3}^{t-2}}{\delta^{2} h_{1}^{t-1}} \\
=\beta\left(w_{1}^{t} h_{2}^{t}+w_{2}^{t}+w_{3}^{t} g_{2}^{t}\right)-g_{2}^{t} w_{3}^{t} \\
+\frac{\left(\theta+h_{2}^{t}\right)}{h_{1}^{t}}\left[w_{3}^{t} g_{1}^{t}-\beta\left(w_{1}^{t} h_{1}^{t}+w_{3}^{t} g_{1}^{t}+w_{4}^{t}\right)-\frac{w_{3}^{t-1}}{\delta}\right] .
\end{gathered}
$$


APPENDIX D. HYPERBOLIC DERIVATIONS

\section{D.3.2 The monopolist's problem}

The first order condition of this problem is

$$
\begin{aligned}
\pi_{1}^{t}+ & \delta \Pi_{2}^{t+1}=0 \\
\therefore \Pi_{2}^{t+1} & =-\frac{\pi_{1}^{t}}{\delta} .
\end{aligned}
$$

The envelope conditions for this problem are

$$
\begin{aligned}
& \Pi_{1}^{t}=\pi_{2}^{t} g_{1}^{t}+\delta \Pi_{1}^{t+1} g_{1}^{t}, \\
& \Pi_{2}^{t}=\pi_{2}^{t} g_{2}^{t}+\delta \Pi_{1}^{t+1} g_{2}^{t}+\theta \delta \Pi_{2}^{t+1} .
\end{aligned}
$$

Solving for the Euler equation: (D.20) $\rightarrow$ (D.21) gives

$$
\begin{aligned}
-\frac{\pi_{1}^{t-1}}{\delta} & =\pi_{2}^{t} g_{2}^{t}-\theta \pi_{1}^{t}+\delta \Pi_{1}^{t+1} g_{2}^{t} \\
\Pi_{1}^{t+1} & =\frac{\theta \pi_{1}^{t}-\pi_{2}^{t} g_{2}^{t}-\frac{1}{\delta} \pi_{1}^{t-1}}{\delta g_{2}^{t}} .
\end{aligned}
$$

Now, (D.24) $\rightarrow$ (D.22) yields the Euler-Lagrange equation:

$$
\pi_{2}^{t} g_{1}^{t}+\frac{g_{1}^{t}}{g_{2}^{t}}\left(\theta \pi_{1}^{t}-\pi_{2}^{t} g_{2}^{t}-\frac{1}{\delta} \pi_{1}^{t-1}\right)-\frac{\theta \pi_{1}^{t-1}-\pi_{2}^{t-1} g_{2}^{t-1}-\frac{1}{\delta} \pi_{1}^{t-2}}{\delta g_{2}^{t-1}}=0
$$




\section{Bibliography}

G. Ainslie. Picoeconomics: The strategic interaction of successive motivational states within the person. Cambridge University Press, 1992. ISBN 0521158702.

L M Ausubel and R J Deneckere. Reputation in bargaining and durable goods monopoly. Econometrica, 57(3):511-532, 1989.

Kaushik Basu. Lectures in industrial organization theory. Blackwell Cambridge, 1993.

Michael R Baye, Keith J Crocker, and Jiandong Ju. Divisionalization, franchising, and divestiture incentives in oligopoly. American Economic Review, 86(1):223-36, March 1996.

G.S. Becker and K.M. Murphy. A Theory of Rational Addiction. The Journal of Political Economy, 96(4):675-700, 1988.

Richard Bellman. Dynamic Programming. Princeton University Press, 1957.

Hassan Benchekroun and Ngo Van Long. Efficiency inducing taxation for polluting oligopolists. CIRANO Working Papers 97s-21, CIRANO, April 1997. 
V V Chari, Patrick J Kehoe, and Edward C Prescott. Time consistency and policy. Staff Report 115, Federal Reserve Bank of Minneapolis, 1988.

Ronald H Coase. Durability and monopoly. Journal of Law E Economics, 15 (1):143-149, 1972.

Chaim Fershtman and Kenneth L Judd. Equilibrium incentives in oligopoly. American Economic Review, 77(5):927-40, December 1987.

Drew Fudenberg and Eric Maskin. The Folk Theorem in repeated games with discounting or incomplete information. Econometrica, 54:533-554, 1986.

F Gul, H Sonnenschein, and R Wilson. Foundations of dynamic monopoly and the Coase conjecture. Journal of Economic Theory, 39:155-190, 1986.

Alain Haurie and Matti Pohlohja. Efficient equilibria in a differential game of capitalism. Journal of Economic Dynamics and Control, 11:65-78, 1987.

Harold Hotelling. The economics of exhaustible resources. Journal of Political Economy, 39:137-175, 1931.

Charles Kahn. The durable goods monopolist and consistency with increasing costs. Econometrica, 54:274-294, 1986.

Larry Karp and David M G Newbery. Intertemporal consistency issues in depletable resources. In Allen V Kneese and James L Sweeney, editors, Handbook of Natural Resource and Energy Economics, volume 3 of Handbooks in Economics, chapter 19, pages 881-931. Elsevier, 1993. 
Finn E Kydland and Edward C Prescott. Rules rather than discretion: The inconsistency of optimal plans. Journal of Political Economy, 85(3):473492, 1977.

D. Laibson. Golden Eggs and Hyperbolic Discounting. Quarterly Journal of Economics, 112(2):443-477, 1997. ISSN 0033-5533.

Nolan H Miller and Amit I Pazgal. The equivalence of price and quantity competition with delegation. RAND Journal of Economics, 32(2):284-301, Summer 2001.

T. O'Donoghue and M. Rabin. Addiction and Self Control. University of California-Berkeley, 1999.

T. O'Donoghue and M. Rabin. Addiction and Present-Biased Preferences. University of California-Berkeley, 2001.

Kenneth Rogoff. The optimal degree of commitment to an intermediate monetary target. The Quarterly Journal of Economics, 100(4):1169-89, November 1985.

Steven D Sklivas. The strategic choice of managerial incentives. RAND Journal of Economics, 18(3):452-458, 1987.

N.L. Stokey. Rational Expectations and Durable Goods Pricing. The Bell Journal of Economics, 12(1):112-128, 1981. 